\title{
Cross-Linguistic Influence in Second Language Acquisition
}

\section{Diplomarbeit}

\author{
zur Erlangung des akademischen Grades \\ einer Magistra der Philosophie \\ an der Karl-Franzens-Universität Graz
}

vorgelegt von

Sarah RIEPL

am Institut für Anglistik

Begutachterin: Ao. Univ.-Prof. Mag. Dr. phil. Margit Reitbauer

Graz, 2015 
To my mum, who, throughout my life, has not only told me that I can achieve anything I want to but who has also shown me how to do it.

To my dad, who is the proudest father on earth. He has supported me in everything I have done so far and will always stand by me, unconditionally. 


\section{STATUTORY DECLARATION}

I declare that I have authored this thesis independently, that I have not used other than the declared sources / resources and that I have explicitly marked all material which has been quoted either literally or by content from the used sources. 


\section{Table of Contents}

1. Introduction 1

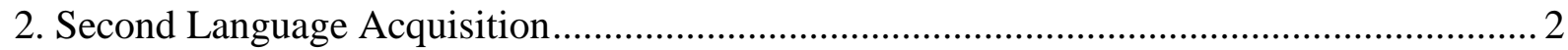

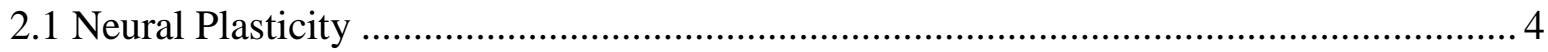

2.1.2 The Critical Period \& Neural Plasticity and Pronunciation .................................... 5

2.1.2 The Acquisition of Sound and Sound Patterns in SLA............................................ 6

2.2 The Critical Period Hypothesis.................................................................................. 8

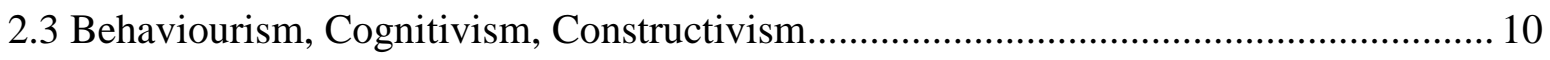

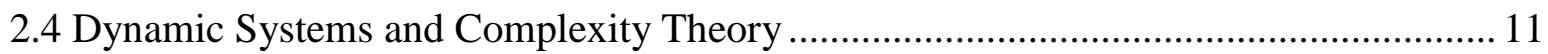

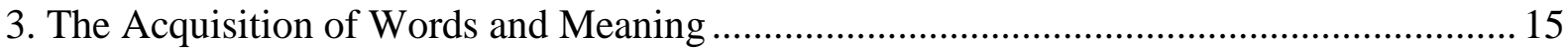

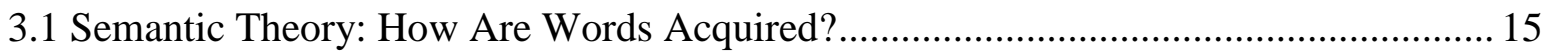

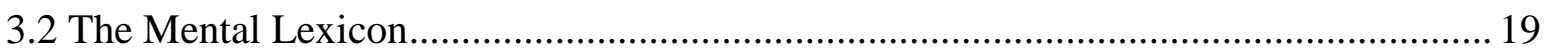

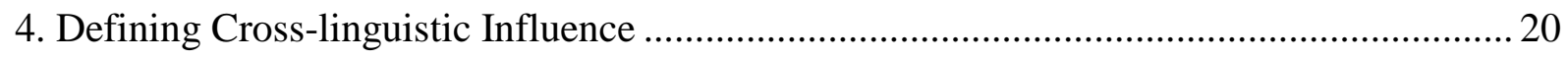

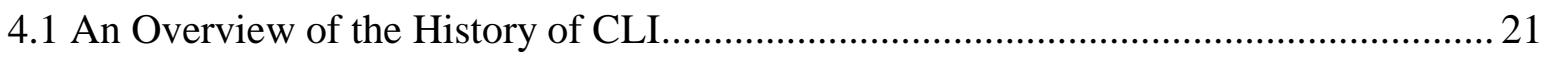

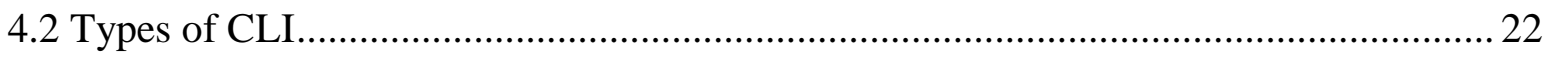

4.3 Factors Determining Occurrence, Intensity and Frequency of CLI ...........................2 25

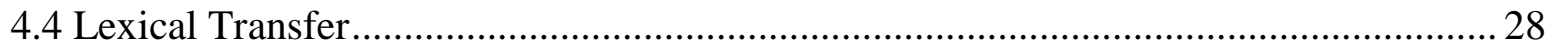

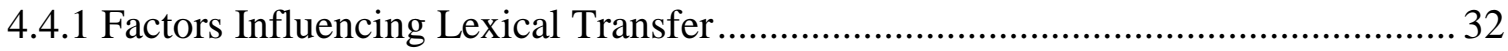

4.4.2 A Study on Lexical Transfer of Fixed Expressions .............................................. 34

4.5 Phonetic and Phonological Transfer..................................................................... 35

4.5.1 Factors Influencing Phonetic and Phonological Transfer ..................................... 36

5. The Influence of New Media on the Mother-Tongue …..................................................... 38

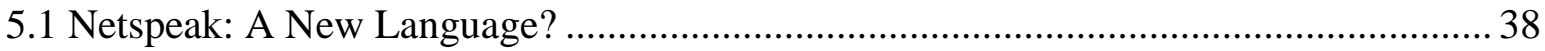

5.2 The Influence of the Internet Language Lexicon on Users' Everyday Language .......... 41

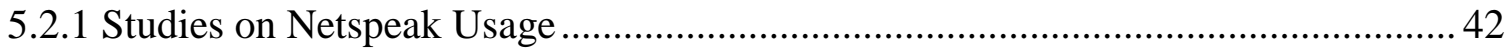

6. Empirical Research: Investigating Phonological, Phonetic and Lexical Transfer .............. 44

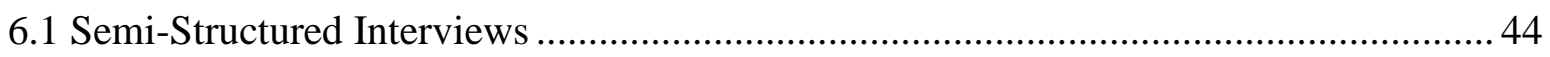




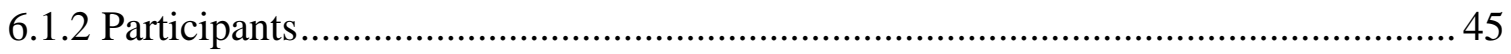

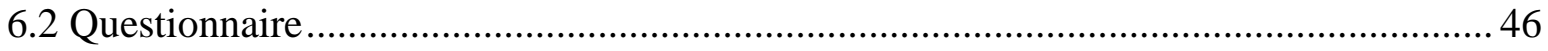

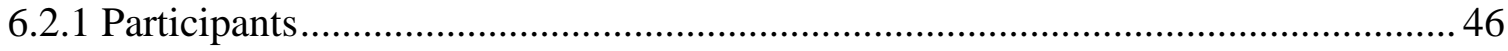

6.3 Phonological, Phonetic and Lexical Transfer From German to English: Two Teacher

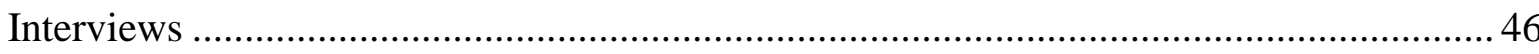

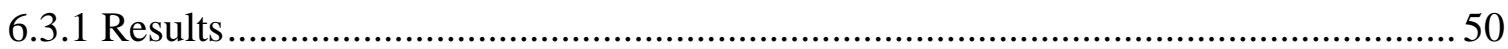

6.4 Transfer from Netspeak of the Second Language English to the Mother-tongue German:

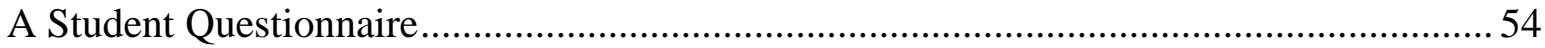

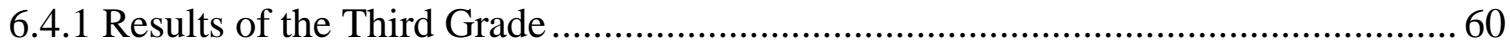

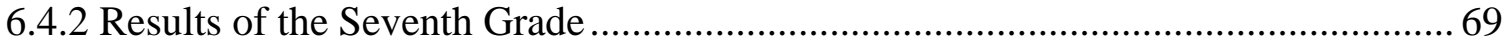

6.4.3 Significant Differences Between Third and Seventh Grade ................................. 78

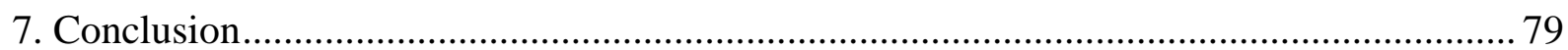

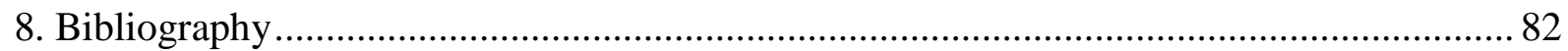




\section{List of Figures}

Figure 1. The Interactive Activation Model by McClelland and Rumelhart ........................... 7

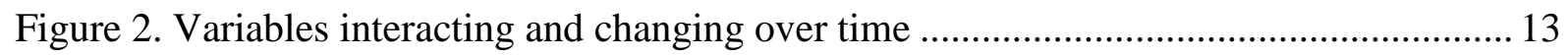

Figure 3. The types of knowledge involved in knowing a word ......................................... 16

Figure 4. A hierarchical model of lexical storage ................................................................ 18

\section{List of Tables}

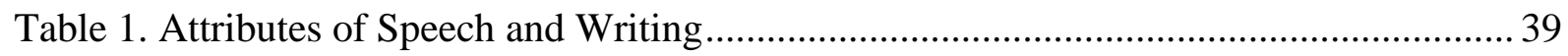

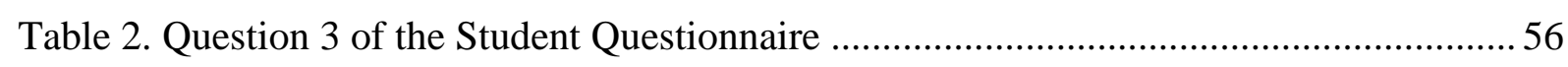

Table 3. Question 5.1. of the Student Questionnaire ............................................................ 58

Table 4. Question 5.2. of the Student Questionnaire ........................................................... 59

Table 5. Third Grade: Netspeak items students have heard of............................................. 60

Table 6. Third Grade: Other netspeak items students have heard of ..................................... 61

Table 7. Third Grade: Netspeak items students use in German writing or speaking ............... 62

Table 8. Third Grade: Students know how to use these netspeak items in German writing or

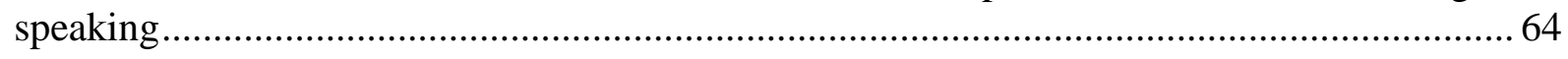

Table 9. Third Grade: Students know what the given netspeak items stand for in English..... 65

Table 10. Third Grade: When students use the given netspeak elements in spoken German.. 66

Table 11. Third Grade: Where students use the given netspeak elements in German writing 67

Table 12. Seventh Grade: Netspeak items students have heard of.......................................69

Table 13. Seventh Grade: Other netspeak items students have heard of ................................ 70

Table 14. Seventh Grade: Netspeak items students use in German writing or speaking ......... 71

Table 15. Seventh Grade: Other netspeak items students use in German writing or speaking 72

Table 16. Seventh Grade: Students know how to use these netspeak items in German writing

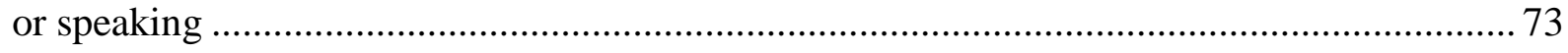

Table 17. Seventh Grade: Students know what the given netspeak items stand for in English

Table 18. Seventh Grade: When students use the given netspeak elements in spoken German

Table 19. Seventh Grade: Where students use the given netspeak elements in German writing .76

Table 20. Comparing third and seventh grade: Students know what the given netspeak items stand for in English .78 


\section{Introduction}

This paper deals with the cross-linguistic phenomenon of language transfer. The idea of mixing different languages either intentionally, e.g. in the hybrid language Spanglish, which is spoken in certain parts of the USA, or unintentionally, is omnipresent nowadays. A great number of people in the world can speak more languages than just their mother tongue. Professional translators can even switch between two or more languages without intermingling them. If even professionals mix up their languages, what about us ordinary people speaking various languages just for fun?

This paper investigates how the first language or any other language that has been learned before the language that is currently learned influences second language acquisition, and vice versa. In this regard, the fairly new approach of seeing language learning as an interplay between dynamic systems is discussed and applied to the issue of cross-linguistic transfer. In addition, general factors influencing language transfer as well as aspects affecting lexical and phonological transfer are explained. In particular, lexical and phonological language transfer from the first language German to the second language English are examined and analysed by means of teacher interviews. This study focuses on both beginners and advanced students. As a third aspect, the impact of very specific English lexical items, namely Internet Language elements, on the usage of the mother-tongue German is discussed. Since pupils in Austria all learn English as a second language in school, I was very interested in finding out how English netspeak influences their native language. For this purpose, pupils of a third and seventh grade of a secondary school (AHS) were tested on their netspeak use in German contexts on the basis of a student questionnaire.

Finally, conclusions are drawn which are hopefully helpful for both language learners and language teachers. 


\section{Second Language Acquisition}

In order to be able to understand Second Language Acquisition, it is necessary to define a few terms first, of which mother tongue seems to be the most important one for this paper. As several definitions state, the mother tongue is the language that is learned from birth, or spoken from early childhood onwards, as compared to languages that are learned later at school or as an adult (cf. "mother tongue" Oxford Dictionaries, "mother tongue" Cambridge Dictionaries Online). The terms native language, mother tongue and first language are used as synonyms in this paper and thus all refer to the first language acquired by a person.

The second language, however, does not concern the mother tongue but any other language that is learned after the first one. It is important to understand that the term "second" does not only refer to the language acquired right after the first one, i.e. literally the second one, but also to all other languages following the native language. This means that second language acquisition (SLA) also deals with third and fourth languages. In addition, SLA does not exclude the learning of a foreign language; on the contrary, linguists understand both instructed language learning in a classroom and language acquisition as result of living in the respective country as L2 acquisition (cf. Ellis 2007:3).

In the second half of the twentieth century researchers began to study how learners acquire a second language. The increasing interest in this topic seemed to be the consequence of the invention and the spreading of the internet. The world has got somehow smaller as it was suddenly possible to reach out to people who did not live close by. Ellis (2007:3) uses the term "global village" to describe the rather new phenomenon that even though the size of the earth is enormous, people can still get in touch with someone from the other end of the world. The only hurdle is the language barrier between the and therefore second language learning has also gained immense importance for the average person. The other reason why people have to acquire a second language is that for most jobs employers require their employees to be able to speak and write in more than their native language. Thus, knowing a language apart from the mother tongue has become an essential part of an excellent education (cf. Ellis 1997:3).

To fully comprehend the topic of this paper it is necessary to clarify the two terms $L 2$ acquisition and second language acquisition. The first refers to the process of acquiring a language other than the mother tongue either inside or outside of a classroom. SLA, on the other hand, refers to the study of people learning this second language (cf. Ellis 2007:3). 
Second language acquisition tries to describe L2 acquisition and explain it by establishing theories. Researchers attempt to find answers to two specific questions in particular: Which processes take place when a person is learning a second language? And why is a second language acquired easily/with difficulties/never..? Concerning the second question, there are several factors, both internal and external ones, that account for different L2 acquisition amongst language learners (cf. Ellis 2007:3).

One external factor Ellis (cf. 2007:4-5) names is the social milieu in which the language is learned. This social aspect is very important for L2 acquisition since it marks how often and in what way the learner can practise the language. This, in turn, affects the attitude the learner develops towards the new language.

Input is another important external aspect that is investigated in SLA as there is no learning without input. SLA examines what kind of input is most efficient for acquiring a second language successfully; if it is, for example, authentic native-speaker communication or rather simplified tasks that make people learn more easily (cf. Elli 2007:5).

Internal factors that can impact L2 acquisition are such that concern the brain and the nature of a person in general. Examples given by Ellis (cf. 2007:5) are differences in cognitive mechanisms, different general knowledge about the world and diversity in communication strategies. One very controversial internal factor is the language aptitude, i.e. the "natural disposition of learning an L2" (ibid p.6). The concept of language aptitude refers to the fact that there are people for whom it is easier to learn new languages than it is for others.

Second language acquisition research focuses on very precise formal items of languages rather than on the overall ability or fluency of a learner. Numerous specific linguistic features are investigated in L2 acquisition such as pronunciation, accent, and vocabulary of the second language. The most common feature investigated in SLA, however, is definitely grammar; a certain grammatical item, e.g. plurals, is chosen by the researcher and then observed in the learner's language over a certain period of time to be able to describe the processes of learning (cf. Ellis 2007:4).

There are several different ways of investigating learning processes involved in second language learning. One option is, for example, to collect oral or written samples of 
learnerlanguage. Then the samples need to be examined closely as they show what learners can already do and what not (cf. Ellis 2007:4).

\subsection{Neural Plasticity}

The researchers Broca and Wernicke found that there are two main areas in the brain which are involved in the processing of language. They examined patients with brain damages to locate the areas in the brain that are responsible for the production and reception of speech sounds. The area which focuses on the production of (coherent) speech is called Broca's area and the one that covers the acoustic aspect of language Wernicke's Area. Other important cerebral regions for language articulation are the primary motor cortex, the premotor cortex and the supplementary motor area (cf. Grodd et al. 2009: 131-133).

The first linguistic theories claimed that the human brain is rigid and inflexible and thus not able to alter itself. In the $21^{\text {st }}$ century, however, researchers can investigate the brain using brain imaging techniques and disprove these early assumptions. Many studies working with brain imaging bring forward sufficient evidence that the brain can and does change in order to adapt to the requirements of external conditions. For this purpose, brain structures and neural mechanisms undergo permanent change. This concept implies that people can easily learn, unlearn and relearn (cf. Wesson 2010, online).

The brain is organised in four major lobes and each of them consists of 200 functional subareas. Yet, before a piece of information reaches its respective brain area, it has to pass through several "stations". There are three categories of information, i.e. auditory, visual and sensation information. The first stop is the thalamus, which lies right in the middle of the brain and is considered the waiting room. After that, the information is sent to the cerebral cortex, where it finds its particular functional area (cf. Wesson 2010, online).

If we want to move, feel and think, our brain does something incredible: The neurons in our cerebric communicate with each other through electrical and chemical processes. If the external stimuli is strong enough, the "electrical impulse 'fires' down the axon" (Wesson 2010, online). At the end of the axon, neurotransmitters which contain the respective information are set free to cross the synaptic gap so that they can dock onto the other neuron and transmit 
their chemical information. This outstanding mechanism allows the human brain to reorganise itself whenever it needs to in order to adapt to the environment (cf. Wesson 2010, online).

A child's brain contains too many of these synapses (connections) when it is born, i.e. a lot more than the adult brain. From the age of two years onwards children gradually lose those that they do not need and therefore not use. This overproduction of synapses might sound positive to some people but the organisation of this chaos demands great physical effort and energy from children as can be proved by their extensive need of sleep. Also, due to this excessive demand, the process of organising can even take longer in a child's brain than in an adult's (cf. Wesson 2012, online).

These findings about neural plasticity imply that the acquisition of a second language can indeed be easier for adults than for children, because of the pre-existing neuronal connections. These synapses, i.e. the pre-knowledge of other languages such as the mother tongue, can facilitate the learning of another language. This would refute the concept the younger the better, which is explained in the next chapter.

\subsubsection{The Critical Period \& Neural Plasticity and Pronunciation}

When Lenneberg introduced the critical period hypothesis, several studies were conducted which focused on language learners' pronunciation. Patowski (1990 cited in Flege 2014:101), for example, observed that immigrants who had come to the USA at the age of 15 or later showed a very strong accent compared to those who had arrived before the age of 15 . He thus agreed with Lenneberg and claimed that for the former group of people it was simply impossible to acquire an accent-free pronunciation because of their advanced age. Scovel (1969, 1988 cited in Bongaerts 2014:133) even suggested that pronunciation was the only linguistic field in which a critical period exists.

Meanwhile, however, many, more recent studies have disproven the claim that learning phonology and phonetics of a new language successfully after puberty is impossible (e.g. Klein 1995). Results of out-dated studies have been criticised as subjects were not randomly chosen but rather selected due to certain factors. This rendered it difficult to also investigate language learners with high language proficiency since they were simply not included in such studies (Long 1990 cited in Bongaerts 2014:136). To achieve a native-like 
pronunciation adults simply have to make a greater effort than children. Klein (1995 cited in Bongaerts 2014:135) also mentions that the motor system, in general, is capable of learning and pronouncing new sounds and sound patterns even after the allegedly sensitive period.

Bongaerts (cf. 2014:137-152) conducted a range of studies on L2 pronunciation and found that it is indeed possible for adult learners to reach the same level as native speakers. In all of his studies he found a small number of people who had started with their L2 as adults but still showed pronunciation on a native speaker level. In addition, Zhang and Wang (2007:152) conclude that when adult language learners have enough linguistic experience, neural plasticity is sufficiently powerful so that the learner can successfully acquire a new system of pronunciation. This presupposes that the language learner is provided with substantial material, also on theoretical phonology and phonetics, as only being exposed to the natural speech does not seem to be enough to acquire a foreign pronunciation effectively. If the input and hence the linguistic knowledge is poor, the person's Native Language Neural Commitment (NLNC) will prevent the brain from accessing the regions which are essential to create categories of the new sound system (cf. Zhang and Wang 2007:152).

\subsubsection{The Acquisition of Sound and Sound Patterns in SLA}

According to Brown and McNeil's (1966 cited in Randall 2007:103) findings, phonological knowledge of words is stored right next to the semantic and lexical information in the brain. They examined the tip of the tongue phenomenon, which explains the cognitive processes when learners are trying to access a word. The particular goal of this study was to find out what kind of information is accessible for speakers in such situations and which one seems to be impaired, and how the different information of the words is interconnected. For this purpose, subjects were put into situations where tip of the tongues were very likely and were asked what linguistic characteristics they knew about the word they were looking for. The results showed that, even though the learners could not remember the exact word, they could retrieve different aspects of the word, namely the first few sounds, the last sounds, the number of syllables and the stress pattern of the words. Applying these results to the interactive activation model of McClelland and Rumelhart (1981 cited in Randall 2007:103) it could be said that the phonological and semantic layer of the respective word is accessible to the 
learner; the lexical level, which would give the exact word, however, is not. The model for the word exacerbate would, for example, look like the following: (Randall 2007:103):

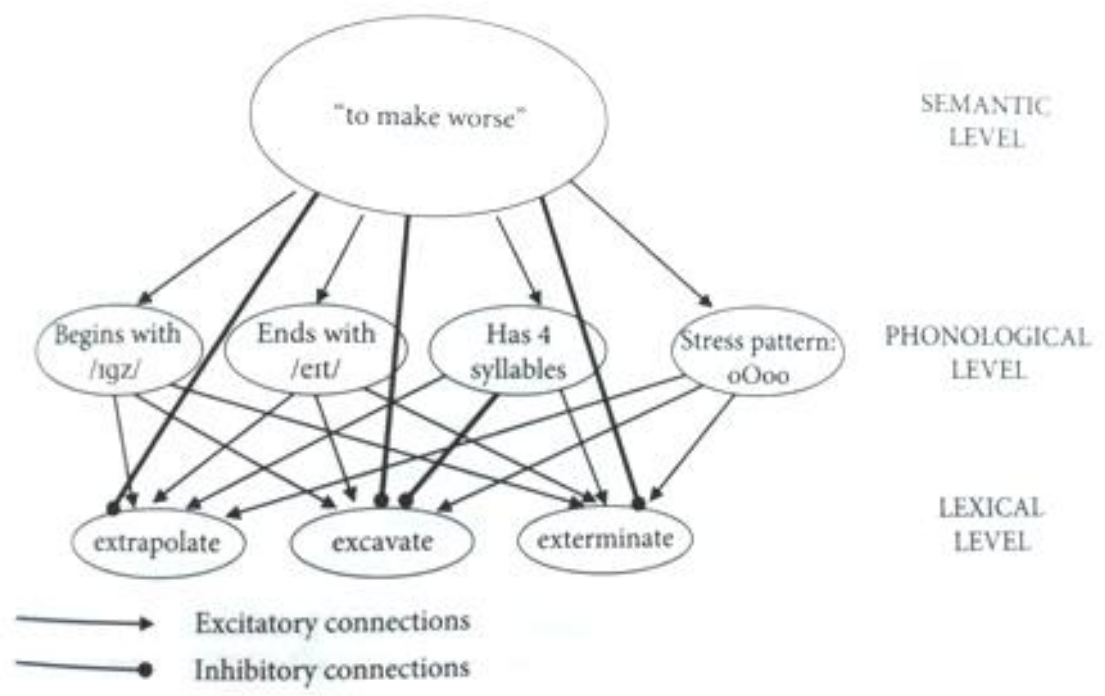

Figure 1. The Interactive Activation Model by McClelland and Rumelhart

(1981 cited in Randall 2007:103)

Randall (2007:104) argues that this theory might not exactly apply to the second language learner. As has been discussed in chapter 3.2. The Mental Lexicon of a Second Language the mental lexicons of different languages are likely to be linked, which would mean that in second language acquisition it is imaginable that the phonological level of a word in the L2 is connected to any other level such as the lexical level of a this word in the L1, and vice versa. Therefore, the access to phonology of L2 words might be much more complex than in first language acquisition.

In English there are several sounds which seem to be particularly difficult for L2 learners since they are fairly different to the sounds of many other languages. Developmental, phonological studies deal with difficulties in the production of sounds and investigate the reasons behind them. Linguists found sounds of the English language that are difficult to pronounce for L2 learners such as $r$, the aspect of voicing and devoicing like in $t / d$ and $p / b$, and, of course, the famous th. Depending on the mother tongue different sounds entail problems for the right pronunciation (cf. James 1988:1-2). 
Common models of acquisition of second language phonology (cf. e.g. Corder 1978:75 cited in James 1988:4) suggest that when people learn the phonology of a second language, elements of the first language's system are by and by exchanged for characteristics of the second language. This means that the first language phonology is indeed important to be able to learn new phonology of another language.

\subsection{The Critical Period Hypothesis}

When it comes to language acquisition, one hypothesis still seems to be as omnipresent and popular as it was in 1967 when Lenneberg introduced it: The critical period hypothesis. It suggests that younger learners enjoy advantages in language acquisition compared to adult learners. They are said to be faster learners and therefore to show better learning results (cf. Scovel 2000 cited in Abello-Contesse 2008:170).

The concept of the critical period originally derives from biology and labels a fixed period in which humans or animals need to learn certain behaviour as it cannot be acquired after this set period. This implies that if a learner does not start language acquisition early enough, he or she will not be able to acquire it well (cf. Singleton 2014:25).

The case of a young girl named Genie was a great support for the critical period hypothesis. When Genie was discovered in 1970, she was thirteen years of age and had up to that moment never been allowed to make any sounds in her home. Neither did she have the opportunity to listen to the radio, TV or other humans in real life, except for her mother when she fed her daughter. Genie was therefore not able to produce sounds or, presumably, understand other people talking. Eventually, the girl learned the language to some extent but she could never reach the same level as people who had started learning a language from childhood onwards. Her acquired skills of communicating in the respective language, even if very limited, seem to disprove the critical period hypothesis as she showed that it is not entirely impossible to learn a language after this phase; however, Genie's case supports the claim that a (first) language can never be fully acquired after the sensitive period as Genie was not able to learn complex grammatical structures (cf. Yule 2010:166). 
In addition, the results of several studies investigating if there is a sensitive period in the second language acquisition seem to support the general concept of Lenneberg. Singleton (cf. 2014:21) lists several studies, amongst them Seliger et al.. (1975) who found that immigrants coming to the respective country before the age of nine were more often thought of as native speakers, whereas those who immigrated at the age 16 or later had the feeling that they had a foreign accent. Piske et al.. (2002), came to the same conclusion, namely that Italians who moved to Canada at a very young age spoke with less accent than those Italians who were already advanced in age when they immigrated.

It seems that some arguments speak for the critical period hypothesis in general. Lenneberg (1967:176) claimed that at the end of the sensitive period a "termination of a state of organizational plasticity linked with lateralization of function" takes place in the brain. His research was, however, limited to first language acquisition, which makes the hypothesis weaker for the specific area of second language learning. For second language acquisition Lenneberg refers us to Chomsky's Universal Grammar Theory, which postulates that there is a scaffold in every human's head which enables him/her to learn a (new) language (cf. Birdsong (2014:3).

One aspect which seems to argue for the sensitive phase hypothesis in second language acquisition is the loss or inaccessibility of Universal Grammar (UG) in older learners. If we assume that ending the sensitive period equals losing the UG, the critical period theory can also be applied to L2 acquisition. In addition, learning strategies might not be as easily accessible for older as for younger learners. A less strict view suggests that UG and learning strategies are not simply lost in L2 acquisition but that it is just more difficult for older learners to acquire L2 parameters. This might be because learning new parameters means to consciously unlearn the existing ones so that a new language structure can be learned (cf. Birdsong 2014:3-4).

However, numerous arguments seem to rebut the critical period concept of Lenneberg. Johnson and Newport (1989 cited in Birdsong 2014:10) showed with their study conducted on immigrants to the USA that there does not seem to be a set period after which a high language proficiency cannot be reached anymore; but rather that when the children's age of arrival is seven years and higher their English proficiency linearly declines. Those subjects who were older than 17 showed totally mixed outcomes on their proficiency tests, which suggests that there is no such thing as a fixed period from two to puberty in which second language acquisition is generally easier or more successful. Birdsong (cf. 2014: 11) concludes from 
these studies that language learning does get more difficult for some people when they grow older, but that, firstly, this is not the case for everyone and, secondly, the decline happens over a life span and not right after a certain age or period.

As Abello-Contesse summarises:

In terms of language pedagogy, it can therefore be concluded that (i) there is no single 'magic' age for L2 learning, (ii) both older and younger learners are able to achieve advanced levels of proficiency in an L2, and (iii) the general and specific characteristics of the learning environment are also likely to be variables of equal or greater importance. (Abello-Contesse 2008:171)

\subsection{Behaviourism, Cognitivism, Constructivism}

When we investigate aspects of second language acquisition, we also need to look at the different psychological approaches to learning in general. Three main theories have been established over the last few decades to describe how people learn, namely behaviourism, cognitivism and constructivism.

Psychologists believing in behaviourism had their research focus on external factors. They investigated the behaviour of humans and animals in an artificially created environment. The so-called trial-and-error theory was the basis of many behaviouristic studies. It says that both animals and humans learn to repeat certain behaviour more often and react more quickly to a given stimulus if this particular behaviour is reinforced, for example by reward. The three essential factors of trial-and-error learning are the stimulus, the response and the altered environment after the subject's response to the stimulus (cf. Randall 2007:6).

Assigning a specific response to a stimulus is called associative learning. This theory also explains several aspects of language learning; by practising again and again the response following the stimulus will be faster and more reliable (cf. Randall 2007:6). If a language learner, for example, looks at cards with different objects on them which he or she has to name in the target language, the subject will be able to recall the words faster after having repeated looking at the cards a few times. 
The behaviouristic approach alone, however, is not sufficient for investigating language acquisition since it does not deal with cerebral processes at all, but simply sees the brain as a black box which is somehow influenced by the environment. Another problematic issue is the fact that most studies were conducted on animals and not on humans. Therefore results cannot be generalized as easily, especially because, when it comes to language, there cannot be found any relevant results in animal studies which can be adapted to humans. However, when behaviourists examine humans and their language use, they claim, for example, that an answer like Yes I did to the question Did you go home? simply is an automatic response to a given stimuli. The brain activity is not seen as essential part of language learning and therefore entirely ignored (cf. Randall 2007:6).

The cognitivists, on the contrary, mainly focus on internal factors of learning, i.e. on the brain and its processes influencing human behaviour. However, the empirical research of behaviourists is still used by the cognitivists to build hypotheses which explain why certain behaviour is shown and what the brain's part isin all this. It is the cognitivist theory which suggests and has also partly empirically proven that a human has different types of memory in his/her brain. The first findings of cognitive studies were not only seen as a milestone for general learning but also for language learning. The only criticisable aspect about cognitivists' findings is that concepts are concluded from individuals' observations. The specific field where the cognitive view and linguistics are linked is called psycholinguistic. Psycholinguists investigate specific behaviour, i.e. language, in a natural environment, to create cognitive concepts (cf. Randall 2007:7).

The third approach to learning is Piaget's (cf. Siegler et al.. 2011:128-129) constructivist theory. It suggests that people learn by using their individual experience and the knowledge they already have. Every learner is seen as an individual as his or her existing knowledge and experience is different to those of other learners. Thus, constructivists acknowledge that learners "have their own needs, goals and contexts" ("Taxonomy of Learning Theories", online).

\subsection{Dynamic Systems and Complexity Theory}

Dynamic systems theory was originally established for mathematical research and has ever since been used to describe phenomena that do not act according to any pattern (cf. De Bot and Laresen-Freeman 2011:9). The dynamic systems and complexity theory of language learning is a fairly new approach in linguistics and is very different from traditional language 
acquisition theories. It says that the processes that take place during language learning are not to be seen separately but as components of a complex adaptive system (CAS). By language processes Beckner et al. (2009) do not only understand cognitive processes but they also refer to the processes of human interaction, i.e. the social aspect. The third interacting factor is all the linguistic knowledge and experience a language learner brings with him or her when learning a new language. As can be followed from this, there are various agents that influence each other at every time during language learning (cf. Beckner et al. 2009:2).

Looking at the different components of language such as sounds, morphemes, words, phrases and clauses, a theory that deals with language as a complex and dynamic system seems suitable for describing the learning of a language. CAS theory does not try to predict specific outcomes but only forecasts that there is interplay between the systems in a learner's head and certain factors in the environment. Furthermore, De Bot and Larsen-Freeman (2011) explain that those systems do not have to change according to certain patterns; on the contrary, they say that these changes often happen irregularly and sometimes even chaotically.

There are nine characteristics of the dynamic systems and complexity theory:

a. Sensitive dependence on initial conditions

b. Complete interconnectedness

c. Nonlinearity in development

d. Change through internal reorganization and interaction with the environment

e. Dependence on internal and external resources

f. Constant change, with chaotic variation sometimes, in which the systems only temporarily settle into "attractor states"

g. Iteration (the present level of development depends critically on the previous level of development

h. Change caused by interaction with the environment and internal reorganization

i. Emergent properties

(De Bot and Larsen-Freeman 2011:11) 
For the topic of cross-linguistic influence, two of the nine aspects seem particularly important, namely complete interconnectedness and chaotic variation. As already mentioned, in dynamic systems theory all components such as syntax and lexis are related to each other. However, the complete interconnectedness goes far beyond the connection of systems within one language; it also implies that systems of different languages at a certain time are interconnected to each other (cf. De Bot and Larsen-Freeman 2011:10-11). This can be seen in the figure below:

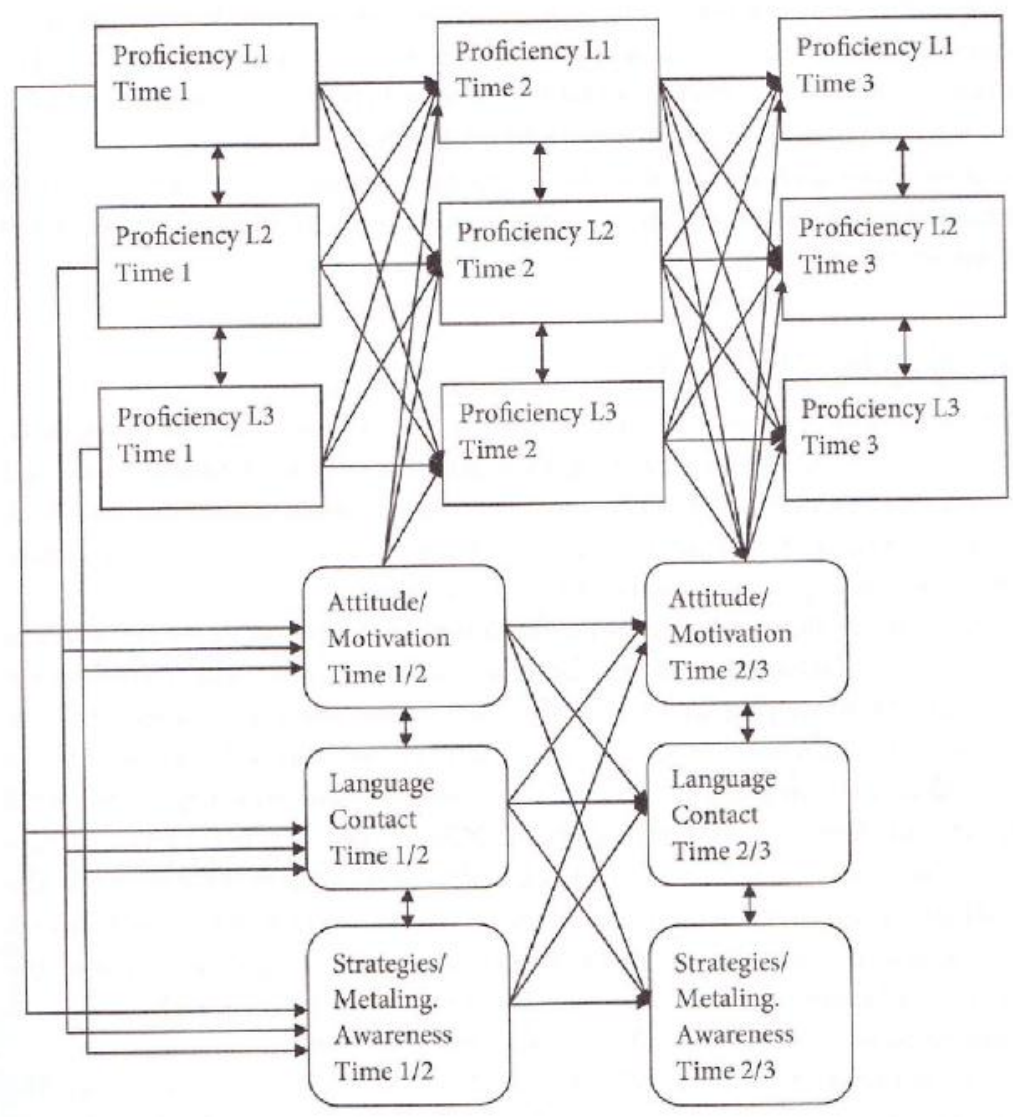

Figure 2. Variables interacting and changing over time

(De Bot et al. 2011:11)

Due to these findings about interconnectedness, the dynamic systems approach is particularly interesting for the investigation of language transfer. Now, that there seems to be evidence for the interdependence between all subcategories of all languages known to a learner, crosslinguistic influence can be based on a L2 acquisition theory which is empirically supported.

The second aspect of complexity theory that helps understand language transfer better is chaotic variation. This factor deals with the unpredictability of language development. 
Language performance varies, which means that the learner at times falls back onto a lower level of proficiency for no obvious reason. Language transfer appears to be similarly unpredictable sometimes. According to CDS theory, some language transfer errors would then be the fault of the different systems that suddenly break down at one moment and build themselves up again in the next (cf. De Bot and Larsen-Freeman 2011:15). 


\section{The Acquisition of Words and Meaning}

Is a word just a 'sequence of letters without any spaces'?

(Hurford 1994 cited in Singleton 2014:38)

As Singleton (2014:38) points out, the term word has indeed two meanings, i.e. 'word' and 'speech' as in Can I have a word with you?. Words can be categorised by several linguistic characteristics and generally by their form and meaning(s).

\subsection{Semantic Theory: How Are Words Acquired?}

When linguists talk about words and the acquisition of them, they often call a word a lexical item or entry as it is not only single words a language learner stores in his or her head but, for example, also whole verb phrases. The next step is to clarify what it means when a person knows a word. Researchers agree that it is not sufficient to only know how to spell and pronounce a word and to know its dictionary meaning; Words should, furthermore, be understood in their various contexts and they should also be used in correct contexts (cf. Lehr, Osborn and Hiebert 2004 in Singleton 2014:39). It is essential for a language learner to know the different meanings a word can and cannot acquire and which other words can be combined with the respective word. It must be understood by the learner that some words can mean something entirely different in a different context and also that some words belong to a formal register and some to an informal. These are only a few aspects that need to be considered when learning new vocabulary (cf. Singleton 2014:39).

Let us examine the word 'test' to illustrate the complexity of vocabulary. It is both a verb and a noun: a test and to test. The noun can refer to many different kinds of tests such as pregnancy test, school test or practical test, which are at the same time typical collocations in English. Typical combinations of the verb would be, for example, to test someone, to test goods and to test someone orally. As can be drawn from this, word storage in the brain is considered a highly complex concept. 
Randall (cf. 2007:102) discusses the different types of word knowledge in more detail and comes up with four categories: phonological knowledge (knowing how a word is pronounced), syntactic knowledge (knowing how to use a word in a sentence), morphological knowledge (knowing how to change a word by adding and erasing components of it) and semantic knowledge (knowing the meaning of a word).

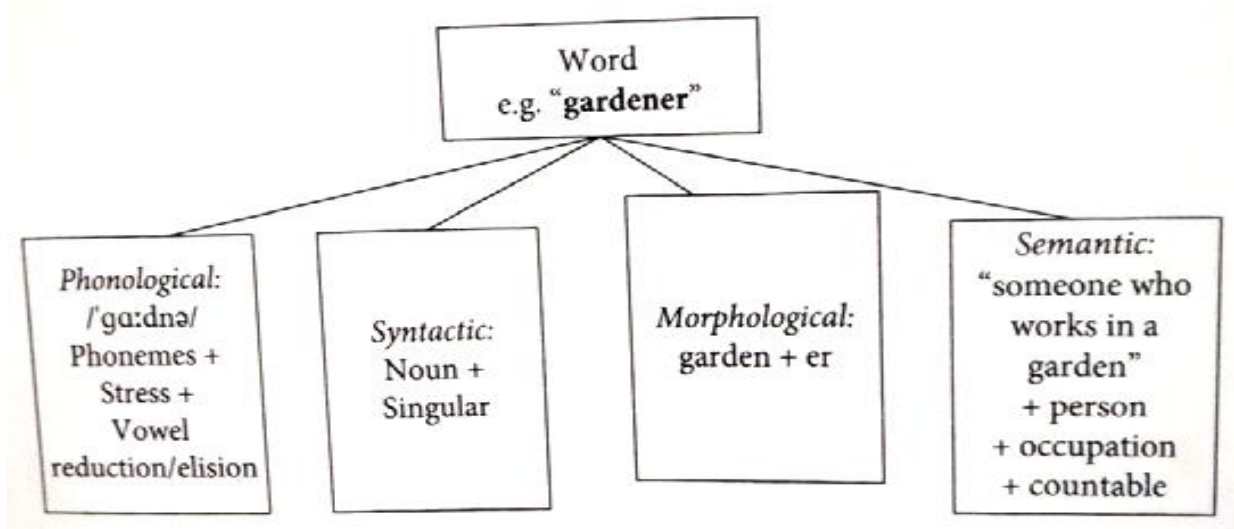

Figure 3. The types of knowledge involved in knowing a word

(Randall 2007:102)

Concepts of phonology acquisition are discussed in chapter 2.1.2 The Acquisition of Sounds and Sound Patterns in SLA. Several studies have been conducted to establish hypotheses of how these different features of words are learned. Since the empirical research of this paper is more concerned with morphological and semantic knowledge, I will focus on these two types in this chapter.

Two main approaches have to be distinguished when discussing models of lexical knowledge: the symbolist and the connectionist or cognitive view. The former claims that the storage of words in the brain is organised like the system of the language itself. This means that in the symbolist view, words are stored with all their grammatical information and an extra syntactic apparatus, which switches itself on when the respective word is heard or seen. Whereas connectionists believe that language is processed similarly to non-linguistic information in the brain. The lexical storage would thus merely contain a list of words which are all interconnected. The main problem with the second approach is, however, that word knowledge cannot simply be the consequence of connections between words as language 
learners also need grammatical information to understand the word in its context, i.e. in sentences or phrases (cf. Randall 2007:106-107).

In morphology there are two suggestions for lexical learning, namely the holistic way and the decomposition of words. The holistic view assumes that if a learner "searches for a word in his brain", he or she immediately looks for the whole word; for example, if the word is decompositions the learner's brain searches for the word as a separate entry. This type of storage seems to be common with words that are often used in the respective language (cf. Rubin et al. 1979 cited in Randall 2007:108-109). The other suggestion of lexical learning is decomposition. It suggests that when a language learner wants to access a word, e.g. decompositions, the word is decomposed into its morphological elements, i.e. prefixes, suffixes and the stem. The prefix in decompositions is de-, the stem is compose and the suffix is $-s$. This does not mean that the brain only uses one of those strategies but it is possible that both are used (cf. Randall 2007:108).

The decomposition strategy is very interesting for second language acquisition as there might be great differences between the mother tongue and the L2. Problems may, for example, occur when the mother tongue has a very limited collection of word stems but a great variety of derivations (prefixes and suffixes); and the second language, however, has many more word stems and less derivations. People of such a different mother tongue would, according to this concept, use the decomposition route in the L2 differently to native speakers of this language (cf. Randall 2007:109).

Concerning the semantic knowledge of words, there are several models of how it is stored in the brain, of which the semantic network model will be explained here. In this model words and word explanations are connected to each other (cf. Randall 2007:110). One example of such a model is the hierarchical network established by Collins and Quillan (1969:241). 


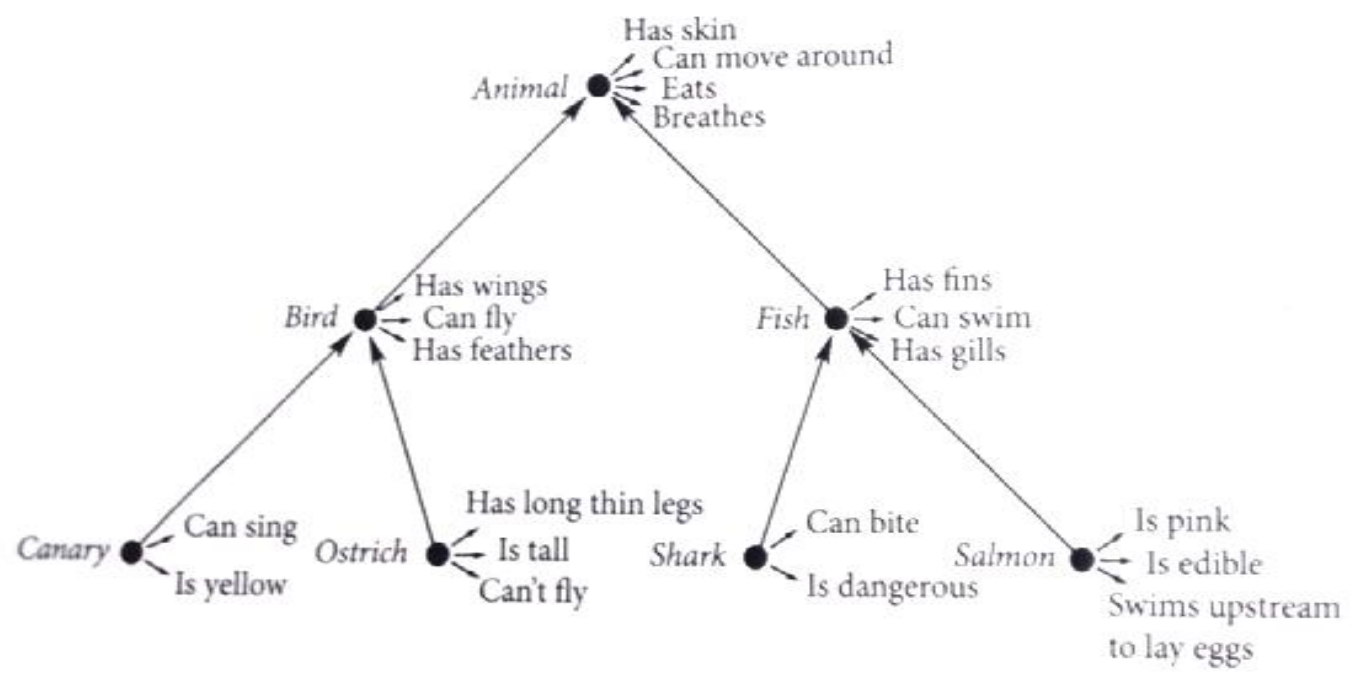

Figure 4. A hierarchical model of lexical storage

(Collins and Quillan 1969:241)

As can be seen in figure 4 above, connections are drawn between more general terms and more specific ones. The semantic elements are connected to each word and, in this example of animals, contain everything from shape to colour to edibility.

Concerning second language learners, it can be said that they not only create such semantic connections within their first and second language but also between the two languages. This is often not successful as some languages are very different, especially in their different meanings of words. This rendering of connections between words of two or more languages has been investigated in several studies. It was, for example, shown that people speaking Hebrew as first language and learning English as a second, draw connections between Hebrew words and English words. The use of this strategy often causes language learners to build words in English which are originally from their mother tongue Hebrew (cf. Singleton 2014:43).

Singleton (cf. 2014:44) also implies that words whose meaning can be visualised easily are learned with less effort than words which cannot be pictured as easily. Words like flower, for example, are acquired more successfully than abstract words such as hypothesise. 


\subsection{The Mental Lexicon}

The mental lexicon, i.e. a storage space in the brain, is a highly interesting component of our language learning processes. It refers to the space in which words and the respective rules for their specific use are stored. It correlates with all the other components of the language processing system and constantly changes its contents, i.e. the words and all the information about them (cf. Handke 1995 cited in Müller 2007, online). Handke (ibid) also mentions that frequent words can be both processed and accessed more easily than words that are not as common.

Singleton (cf. 2007:3), in his article, discusses if there is only one huge mental lexicon for both the first language a person acquires and all the other tongues that are learned subsequently to the mother tongue or whether there is a separate lexicon for every language. The author agrees with many other researchers that the mental lexicons of different languages seem to be, at least to some extent, interconnected. Cook (1992 cited in Singleton 2007:3-4) lists three convincing arguments for the integrationist approach:

1. The time it takes a person to react to a word correlates with the rate of occurrence of its cognate in another language known to the learner (cf. Caramazza \& Brones 1979 cited in Singleton 2007:3).

2. The similarity of morphemic items in two known languages has an impact on the learner's accomplishments in translation tasks (cf. Cristoffanini et al. 1986 cited in Singleton 2007:4).

3. When bilinguals see an interlingual homograph, they retrieve the meaning of both languages and not only of the language being used at that moment (cf. Beauvillain\& Grainger 1987 cited in Singleton 2007:4).

These findings prove that the mental lexicons of different languages are not simply separate systems that act autonomously. Nevertheless, this does not mean that there is only one giant lexicon in the brain for all languages a person knows. Multi-linguals, for example, are able to distinguish between their languages and mostly manage to use only one at a time (cf. Cook 2003:7). In cross-linguistic studies, this theory plays a very important role as sometimes learners are simply not able to totally ignore other languages stored in their brain and therefore transfer items from one language to another. 


\section{Defining Cross-linguistic Influence}

Odlin (cf. 1989:25) outlines four main problems that make it rather difficult to define the term transfer. First of all, transfer is not merely the development of habits. While behaviourist theories seem to claim that learning a new language automatically means adopting new habits and thus to lose old ones of the first language, it is clear that there is no need to replace any item of the first language just because a new language is learned. Therefore Odlin (cf. 1989:25) concludes that behaviouristic approaches cannot be essential for research on transfer.

Secondly, the author points out that interference cannot be an explanation for transfer either. His explanation is quite simple: While the concept of interference seems appropriate for some areas of second language output such as phonological mispronunciations, it cannot stand for the term transfer as such. The reason for this is that interference only describes negative transfer but since there is also positive transfer in L2 acquisition, the word interference is misleading when used as a synonym for all types of transfer (cf. Odlin 1989:26).

The third issue Odlin mentions is that of the wrong assumption that language transfer is just "the result of falling back on old knowledge, the L1 rule", because the appropriate rule has not yet been learned in the new language (Krashen 1983:148 cited in Odlin 1989:26). This cannot be a sufficient theory either, as it disregards the fact that for some people it is much easier to learn certain languages from the very beginning onwards than for others. A Spanish person, for example, will have less difficulties learning Italian than a Chinese person learning Italian, due to the similarities or lack of similarities between the native language and the new one. In addition, there is not always a clear L1 rule that explains the transfer to the new language.

The fourth problematic aspect Odlin (cf. 1989:27) addresses is that transfer does not automatically relate to the native language but can also concern a dyad consisting only of a second and third language. The focus of transfer studies has thus changed over the years as can be seen in the next chapter.

Even though there seem to be severe problems with defining the term transfer, Odlin coined a definition that seems to work with all four proposed issues: "Transfer is the influence 
resulting from similarities and differences between the target language and any other language that has been previously [..] acquired." (Odlin 1989:27).

The term cross-linguistic influence (CLI), in contrast to language transfer, is easier to define. It simply includes influences of all languages learned on all (other) languages learned. In Sharwood's words, cross-linguistic influence is "the influence of the mother tongue on the learner's performance in and/or development of a given target language; by extension, it also means the influence of any 'other tongue' known to the learner on that target language" (Sharwood 1994:198). De Angelis (2007:19) in her definition, gives further specific linguistic areas where CLI is likely to occur: CLI is "the influence of prior linguistic knowledge on the production, comprehension and development of a TL [target language], which can affect various linguistic levels, such as lexis, phonology, morphology or syntax".

\subsection{An Overview of the History of CLI}

In the preface of Odlin (1989:ix-x), Long and Richards make it clear that it is quite difficult to identify the exact beginning of language transfer research. What can be said, nevertheless, is that at some point during the middle of the 20th century, American linguists such as Charles Fries and Robert Lado started to do extensive research on cross-linguistic influence. Robert Lado (1957:2) wrote:

[..] that individuals tend to transfer the forms and meanings, and the distribution of forms and meanings of their native language and culture to the foreign language and culture--both productively when attempting to speak the language and to act in the culture, and receptively when attempting to grasp and understand the language and the culture as practised by natives.

This quotation lets us assume that CLI was, back then, already highly interesting for researchers. They seemed to have quickly realized that this phenomenon plays a crucial role in L2 acquisition and therefore also in teaching.

The fact that many papers on CLI were written from the middle of the 20th century onwards, however, does not mean that linguists had not discussed cross-linguistic influences 
before the 40s; on the contrary, they are said to have already thought about this complex topic in the 19th century (cf. Odlin 1989:6).

Later in the 60s, the interest in CLI decreased as it was believed that making errors in (second) language learning was merely part of "the creative construction process" (Long et al. in Odlin 1989: ix), instead of the fault of language transfer. Some linguists even negated the existence of cross-linguistic influence in language learning at all, in favour of universalist theories.

De Angelis and Dewaele (cf. 2011:vii) explain that the interest in the field of language transfer has increased again over the last 20 years. The content of this research, however, has slightly changed or rather broadened, compared to the research conducted during the 20th century. In the 1980s/90s, the focus did not only lie on the influence of the mother tongue on other languages anymore, but language transfer was also proven to take place from non-native languages to the first language and even between second, third or $\mathrm{n}$ languages themselves, disregarding the first language as a whole.

Numerous studies on CLI have been conducted up to this point and many more are to come. There is already substantial evidence that the phenomenon of language transfer emerges in many different areas of second language learning such as phonology, lexicon, syntax and pragmatics (cf. De Angelis and Dewaele 2011:vii).

\subsection{Types of CLI}

It becomes clear in several definitions of CLI that cross-linguistic influence does not only focus on the theory of one language influencing another language. For this reason De Angelis (cf. 2007:20-21) coined two terms that describe the different types of CLI. The one-to-one type, seen as what is traditionally understood by the term CLI, has its focus on the influence of just one language on another. The combined CLI or many-to-one type, on the other hand, refers to the impact of at least two different languages on a target language at the same time. In the case of third language acquisition, it is however fairly difficult to attribute crosslinguistic influence to one specific language among several other languages of the learner (cf. Eva-Maria Wunder 2011:107). 
As mentioned in chapter 2.1.Defining language transfer and cross-linguistic influence, there is both positive and negative transfer in language learning. Positive transfer means that one specific linguistic element exists in both the language that influences the target language and the target language itself (cf. Eva-Maria Wunder 2011:107-108). This phenomenon helps learners to acquire a new language as they already know certain linguistic aspects from their mother tongue/other second language which are similar or even identical in the new language. Odlin (cf. 1989:36) gives several examples to illustrate this beneficial type of transfer. Lexiswise, similar vocabulary in the native language and target language is supposed to decrease the time a learner needs to improve his or her reading comprehension. Concerning vowel systems, it is believed that the closer such phonological systems of different languages are the easier it is for learners to identify the vowels of a new language. Similarities in writing systems seem to facilitate reading and writing in the target language. The last example Odlin (cf. 1989:36) presents is that of a similar syntax; if the target language has a similar syntactical structure to a previously learned language, articles, word order and relative clauses are easier to understand for the language learner.

Negative transfer, however, exacerbates the learning of a new language since items such as grammatical structures or vocabulary are taken over from the mother tongue/other second language which are yet not the same in the new language (cf. Eva-Maria Wunder 2011:107). Thus, negative transfer can be seen as making mistakes because of the influence of L1 or any other language learned before the current language.

Odlin (cf. 1989:36-38) differentiates between four different types of negative transfer, the first of them being underproduction. Linguists speak of underproduction when a certain structure of the target language is only used very seldom or even not at all. One form of this category of negative transfer is avoidance. The author suggests that if a linguistic item is too different compared to items of the native language, language learners will avoid using this particular linguistic feature. One can see this in Schachter's (cf. 1974 cited in Odlin 1989:37) example where Japanese and Chinese students used fewer relative clauses than students with a mother tongue that contained a more similar relative clause structure. Additional evidence on underproduction was found by other researchers such as Kleinmann (1977).

Another type of negative transfer is the so-called overproduction. It is sometimes seen as the consequence of the previously mentioned underproduction, as overproduction is a way of compensating for the former. If we expand the example of the Japanese and Chinese speaking students, the following can be observed: Due to the underproduction of relative 
clauses the students might use simple sentences too often and thus infringe rules of written English. Another example Odlin (cf. 1989:37) gives is that American English speakers tend to transfer their rules of apologizing, i.e. apologizing very often, into Hebrew, where apologies are not as common as in American English.

Odlin's third subcategory of negative transfer is called production errors. Three types of production errors are known that can be attributed especially to similarities and differences in the native and target language: substitutions, calques and alterations of structures. The first explains the use of linguistic items of the mother tongue in the target language. If a Swedish learner of English, for example, uses the word "bort" instead of the English word for it "away" in the sentence But sometimes I must go bort it is called substitution (cf. Ringbom 1986 cited in Odlin 1989:37).

Production errors where a language structure of the mother tongue is simply adapted to the target language are called calques. For example, there are two sentences that are identical in their meaning but different in their language and thus should also be distinctive in their form. For example, in a study conducted by Fantini (1985), a child, translated an English phrase into Spanish using the exact same structure even though the phrase is different in Spanish: Vamosrápido a poner el fuegoafuera. Let's quickly put the fire out. The correct phrase for putting the fire out would be extinguir el fuego but the child adapted the English language structure to Spanish (cf. Fantini 1985 in Odlin 1989:37).

Numerous other examples of production errors can be attributed neither to substitutions nor to calques but belong to a third subcategory, namely alterations of structures. Odlin (cf. 1989:38) claims that even if it is not visible at first glance there is often transfer from the native language. Examples would be alterations in stress patterns in the L2, which seem to be influenced by the learner's L1, even though the rule the speaker applies does not exist in his or her mother tongue as such.

The fourth type of negative transfer in language learning is, according to Odlin, misinterpretation. It suggests that sometimes previously learned language structures can influence the comprehension of the target language. In this case, learners interpret what is said in the target language very differently to what native speakers of the learner's target language would infer. This can for example happen because of misinterpreting phonology when the learner mishears the spoken words and relates them to the phonology of the native language instead of the target language. 


\subsection{Factors Determining Occurrence, Intensity and Frequency of CLI}

There are several general factors that have an influence on language transfer, the five major ones being the foreign language learning situation, some specific structures predestined for cross-linguistic influence, the stage of interlanguage, the age of the learner, and the concept of similarity. (cf.; Arabski 2006:13-14, Gabrys-Barker 2006: 144, Odlin 1989:3-4, Ringbom 2006:36-54) The aspect of interlanguage and its influence on language transfer will be further investigated in the chapter on lexical transfer.

First of all, the most general aspect that affects linguistic transfer from one language to another to a certain extent is the foreign language learning situation itself. It makes a great difference whether a person is completing a grammar task in which he or she is focusing on a specific grammar rule, or whether he/she is speaking in an actual conversation. In the former situation there will be fewer transfers from L1 than in the latter as the learner is concentrating on one particular item and is trying to apply it. Within a conversation, however, the person tends to focus more on the semantics of his or her utterances, thus neglecting other linguistic norms such as grammar rules of the language that is produced at that moment. This, in turn, is likely to lead to more language transfers from a previously learned language to the one currently used. (cf. Arabski 2006:14).

Secondly, some specific structures of a certain language are especially prone to be transferred to another language. Arabski (cf. 2006:14) shows this by means of the English and Polish language. In this example, a few linguistic elements such as word order, tense system and lexis are more likely to be transferred from Polish to English than other linguistic structures. In addition, the probability of transferring pronunciation from one language to the other is very high in language acquisition. This is the case because the usual language learner is surrounded by the sounds of his or her native language most of the time (ibid:4).

The third factor playing a role in most areas of cross-linguistic influence is the development of the so-called interlanguage (cf. Arabski 2006:14). The concept of interlanguage was introduced by Selinker (1972) and describes the stage at which a language 
learner does not think and write in his/her L1 anymore but has not yet reached the system of the L2 either (cf. VanPatten and Benati 2010:2). There are periods in the process of acquiring a second language when it is more likely to transfer linguistic items to the second language than it is in other periods. Arabski's study (2006) investigating Polish people learning the English language, for example, shows astonishing results: Polish people who learn English are influenced by their mother tongue mainly at the basic level of their learning process, yet not at the beginning, i.e. the imitation stage, or the advanced level. This suggests that as soon as language learners have reached a considerable standard in their second language, structures of the L2 are cemented in the learners' heads and can therefore not be influenced as easily by the L1 anymore.

Another important aspect which seems to have an impact on cross-linguistic influence in (second) language acquisition is the age of the learner, as discussed thoroughly in chapter 2.2 The Critical Period Hypothesis. There is a great number of linguists that support the theory that the younger a language learner is the better. Odlin (cf. 1989:136-137) states that age plays a role in some language transfers indeed, as several studies on both phonological, phonetic, lexical and syntactical transfer have shown.

There is, however, also evidence that it is not always the age of the learner that predestines the degree of transfer but rather the time spent in the respective country. One English girl, for example, only started learning Arabic when she was 21 but reached a nativelike level in the language, which means that language transfer did not seem to be a problem for her, even though she began learning the language rather late. The reason seemed to be that she had already been living in Cairo for 26 years when she was tested (cf. Ellis 2007:68).

As mentioned above, the concept of the younger the better is not without controversy anymore; this also accounts for the assumption that the younger a second language learner is the less cross-linguistic influence he or she will have to deal with in his or her second language. Numerous studies have been conducted on pronunciation, lexis and syntax to investigate the link between the age of a second language learner and language transfer (cf. Odlin 1989). On the one hand, many researchers such as Oyama (1976) found evidence that the younger a learner is the higher the probability that he or she reaches a native-like level of pronunciation. It is, thus, indicated that, at least in pronunciation, cross-linguistic influence plays a more relevant role when the language learner is at an advanced age. On the other hand, studies conducted by linguists such as Neufeld (1978) seem to disprove this connection. They discovered that adult learners can, after all, achieve the same or even a higher level of 
pronunciation compared to young learners. Purcell and Suter (1980) infer from their study that other factors such as the respective time spent in the country where the language is spoken are much more relevant than the age of the language learner (cf. Odlin 1989:137-138). As can be drawn from this, the connection between age and L2 acquisition in general is not completely clear.

The fifth aspect that has been proven to influence language transfer considerably is the similarity of the different languages. Hakan Ringbom (cf. 2006:36) emphasizes the importance of understanding the different types of similarity when speaking about transfer. As Corder pointed out quite some time ago: "In order to compare anything the dimensions or categories used must be applicable to both objects" (1973: 234 in Ringbom 2006:36). This is why it is essential to know the three different categories of cross-linguistic similarity. Before listing these three types, however, it has to be added that sometimes there is a difference between similarity and perceived similarity by the learners. In addition, the different stages of learning, different modes of learning, and the different individual learner have to be considered when investigating cross-linguistic similarity.

There is, first of all, the similarity relation, which facilitates language learning. Similar elements in different languages make it easy to know and use these elements correctly in the new language too. Especially learners of related languages benefit from this phenomenon. In Germanic languages, for example, numerous similar or even identical structures exist throughout different languages and thus make it easier for learners to learn another Germanic language (cf. Ringbom 2006:37). The similarity relation could be seen as another term for positive transfer in transfer studies as it describes the same process.

The second type of similarity is the difference relation, which on the one hand helps and on the other disturbs second or third or $n$ language learning. This is because items have both similarities and differences at the same time. For reasons of clarity I will summarize the example given by Ringbom (cf. 2006:37): A Swedish learner of German will soon notice that in German there are three grammatical genders. Even though in Swedish there are only two, it will still help the learner to understand and apply the three genders in German as the person is used to having grammatical genders in general.

The third category of similarity Ringbomlists in his article is called zero relation(cf. 2006:37). In this case, there are no similarities to a specific aspect of the target language and other languages previously acquired. This means that the learner has to make a considerable 
effort to gain the new linguistic knowledge. An example for zero relation are the grammatical genders, and their existence in German and their non-existence in English. Thus, English speaking people have to learn the grammatical genders in German from the very beginning since they do not have any association with this particular item in their L1 or any other language previously learned.

\subsection{Lexical Transfer}

"[..] there are enormous quantities of evidence for the influence of the L1 on IL (interlanguage) when it comes to lexis" (Kellerman 1987:42)

As explained in chapter 4.2. Factors determining occurrence, intensity and frequency of CLI, one can distinguish between positive and negative transfer. The first one facilitates L2 acquisition by transferring items from the first language or another language previously learned to the new language. In terms of vocabulary this means for example that if there is a word in one's native language that resembles a word in the new language which has, however, not been dealt with it can still be understood by the learner because he/she can draw conclusions from the existing linguistic knowledge of the mother tongue.

Researchers have always suggested that similarities and differences in both word forms and word meanings strongly influence how quickly a foreign language can be acquired. It seems logical that languages with similar vocabulary such as French and English (e.g. the two words justifier and justify) are easier to acquire when one of those languages is already known to the learner (cf. Odlin 1989:77). When Sweet (1988/1972) studied this topic by investigating the differences between European people learning another European language and Europeans acquiring an Oriental language he remarked:

Mastering the vocabulary of most European languages means simply learning to recognize a number of old friends under slight disguises, and making a certain effort to learn a residue of irrecognizable words, which, however, offer less difficulty than they otherwise would through being imbedded in a context of familiar words. The higher vocabulary of science, art, and 
abstract thought hardly requires to be learnt at all; for it so consists either of Latin and Greek terms common to most European languages or of translations of them. (1988/1972:64-65)

He thus suggests that learning the vocabulary of a foreign language which is related to a language previously acquired is much easier than if the lexis of the two languages does not show any similarities. In this way, Sweet (cf. 1988/1972:65) continues, languages with vocabulary that is not connected to European languages such as Arabic and Chinese are far more difficult to acquire for a person who speaks a European language. In this case, lexical items have to be learned by heart as it is not possible to draw any conclusions from existing lexical knowledge. When the learner has then finally acquired sufficient grammar to understand a text written in simple prose, he or she will soon realize that it is necessary to learn different grammar items again to understand different (and more complex) texts.

In 1976, Sjöholm (cited in Odlin 1989:78) conducted a study on positive crosslinguistic influence, especially looking at the lexis of English learners. The researcher observed that Swedes scored better in vocabulary questions about English than Finnish people did. The reason for this outcome might be that there are more cognates in English and Swedish than there are in English and Finnish.

Ard and Homburg (1983 cited in Odlin 1989:78) also investigated positive lexical transfer but took the research to an even higher level in finding out what kind of lexical items in particular the learners found easy. The general outcome of their study was the same as Sjöholm's (1976), the only difference being that they dealt with different native-languages: Spanish people achieved better results in English vocabulary tasks than Arabic speaking people. The researchers discovered that the Spanish subjects found especially those English words easy that had identical or at least similar spelling to the Spanish words. Ard and Homburg (1983 cited in Odlin 1989:78) further claim that not only do language learners have the advantage of identifying cognates easily in a foreign language if the L1 is related to the new language, but they thus also have more time they can spend on the unfamiliar words they encounter.

Odlin (1989:79-80) states that positive lexical transfer can especially be identified in reading comprehension. Several studies seem to prove that learners of a foreign language which is similar to their mother-tongue can deal with texts containing challenging vocabulary 
much earlier than other learners whose first language does not show any similarities to the second language.

Negative transfer, however, exacerbates the acquisition of a foreign language as certain linguistic features of a previously acquired language can have a negative influence on the more recently learned language; the former interferes with the latter. Ringbom (2001 cited in Gabrys-Barker 2006:145) states that negative lexical transfers can concern both the form and meaning of words. Furthermore, he suggests five different categories for lexical transfer errors, namely language switches, coinages (hybrids and blends), deceptive cognates, calques, semantic extensions.

Language switches are seen as a transfer of form and can be observed in both second and third language learning. According to Ringbom (2001:65 cited in Gabrys-Barker 2006:145) this type of mistake, is, at least in L3 acquisition, caused by an "insufficient awareness of intended linguistic form, instead of which (a modified form of) an L2 word is used". This means the language learner simply uses a word or phrase from another language because he or she does not know the form of the respective item in the target language; the learner thus creates a lexical item that does not exist in the target language. For this reason, this transfer error is also called coinage. The creation of such a foreignised or coined word is a common strategy in L2 and L3 acquisition and is called foreignising (cf. Ringbom 2001 cited in Gabrys-Barker 2006:145). Hybrids and blends, subcategories of coinages, describe words which are created by combining two or more morphemes; hybrids can contain both native and foreign elements such as "inter" (Latin) and "language" (Latin/French) in the hybrid word "interlanguage".

The third lexical transfer error, deceptive cognates, also relates to the form of words and is known as false friends. The reason for producing false friends is the formal similarity between the two languages. Ringbom (cf. 2001 cited in Gabrys-Barker 2006:145) explains that the main focus lies on the linguistic form of the word since there is a similar word in the L1 or L2 that influences the correct output of the target language. A typical example in Spanish/English would be "embarazada" which does not mean "embarrassed" but "pregnant". Another common false cognate is "éxito" which means "success" and not "exit" as some language learners might expect. A third example would be "libraría" which is not the library but the book shop; the library is called "bibliotéca" in Spanish. As can be reasoned here, false friends are very common in many languages (cf. Gabrys-Barker 2006:145). 
Odlin (1989:79) distinguishes between three types of deceptive cognates. The first category contains those cognates that are only partially correct in both languages and are therefore often misused. Common cognates of this category are "to succeed" in English and "suceder" in Spanish. While "succeed" can be used in numerous different contexts, the use of "suceder" is limited to certain phrases (cf. Anthony 1952 cited in Odlin 1989:79).

Secondly, lexical cross-linguistic influence is not restricted to words and their form but can also concern the meaning of words. The linguistic form of those words does not have to be similar or identical in this case (cf. Odlin 1989:79). When Ringbom (cf. 1987:117) examined Finnish students learning English, he observed a very interesting mistake made by one of the students. The subject said "He bit himself in the language.".This error can easily be explained through the linguistic rules of his mother-tongue, as in Finnish there is only one word ("kieli") for the two English words "language" and "tongue".

The third type of deceptive cognates that are caused by negative transfer deals with grammatical restrictions of words/languages. Words can be similar in their meaning but still differ in their use as there are different rules for applying them (cf. Odlin 1989:79). In one of Adjemian's (1983 cited in Odlin 1989:79) studies for example he noticed a fascinating error made by a French student in an English test. The student wrote "At sixty-five years old they must retire themselves because this is a rule of society." Now, the word "retire" is a correct cognate in French and English indeed; only in French, however, it requires a reflexive pronoun to accompany the morpheme "retire". In English, on the other hand, "retire" is used on its own and therefore the word is used wrongly in this sample.

Ringbom (2001 cited in Gabrys-Barker 2006) suggests the two terms calque and semantic extensions to describe meaning transfer from one language to another. Calques are, according to him, literal translations of difficult words and phrases, whereas semantic extensions include the use of words in a wrong context, overextensions and near synonyms.

Odlin (cf. 1989:79) seems to doubt that lexical transfer due to semantic similarity is as common as cross-linguistic influence because of similarity of linguistic forms, but also says that there is no clear answer to this question yet. However, what contrastive analysis research on lexical similarities has proven so far is that identifying both true and deceptive cognates is more difficult than we would think; and even if language learners manage to recognize such cognates, they might not always believe that there is a true relationship between those words and might thus not be able to use this advantage for their language learning. 


\subsubsection{Factors Influencing Lexical Transfer}

In chapter 4.4. Factors determining occurrence, intensity and frequency of CLI, numerous factors have been given that seem to play a role in language transfer. In this chapter, aspects are discussed that seem to account for cross-linguistic influence in particular in the field of lexis. The following four general and three very specific factors are believed to have a special impact on lexical transfer in L2 acquisition.

The first four aspects can be described as rather general states of the learner's mind. First of all, if a certain item, for example a word or a collocation, has not been learned yet due to too little input or none at all, it will be more likely for the learner to transfer those items from a language already known to him or her to the new language (cf. Gabrys-Barker 2006:144).

In another situation, in which CLI is more likely, the focus lies on the accessibility and activation of the brain. In this case, the learner correctly absorbs the new item indeed, but is not able to access or activate it when he or she needs it; language transfer will presumably take place here to fill such gaps in the new language. Common tasks in which a learner can have difficulties with accessing lexical items are spontaneous tasks such as speaking activities (cf. Gabrys-Barker 2006:144).

The third general factor influencing lexical transfer is the lacking knowledge of rules that makes it difficult for the learner to use a lexical element in a way different from what he or she has been taught (cf. Gabrys-Barker 2006:144).

Fourthly, cross-linguistic influence in lexis is more likely to occur when rules can only be explained very generally. Not knowing exactly when to use what kind of word or phrase can be very demanding for language learners. An example here would be the indefinite and definite articles in English (cf. Gabrys 1999 cited in Gabrys-Barker 2006:144).

One of the very specific aspects that seem to have an influence on lexical language transfers is markedness. Unmarked structures of a language are said to be 'natural' or 'basic' and therefore occur quite often in a language. According to Chomsky this category would be 
ruled by Universal Grammar (cf. Ellis 2007:70). The theory of UG claims that there are certain structures in the human brain from birth on that enable people to learn a language and facilitate the acquisition process. It is, however, rather controversial and links to the hypothesis of "the younger the better in language learning" (see also: age as a factor determining language transfer). The marked structures, on the other hand, are believed to exist outside of UG and are therefore more difficult to acquire for language learners (cf. Ellis 2007:70).

Researchers agree that the markedness of structures can predict the occurrence of lexical language transfer (cf. Arabski 2006, Kellerman 1983, Ellis 1997). Numerous studies have shown that unmarked structures, i.e. basic structures, are more likely to be transferred from the first language than marked structures (cf. Kellerman 1983 cited in Arabski 2006:14).

The second specific factor affecting lexical cross-linguistic influence is linguistic awareness. As is commonly known, one can distinguish between knowing a language and knowing about a language. Generally, researchers do not entirely agree on the role of linguistic awareness. Odlin (cf. 1989:140), nevertheless, claims that metalinguistic awareness does play a role in cross-linguistic influence, even though it cannot yet be explained how exactly.

Proficiency, the third very precise aspect, seems to influence language transfer on the level of lexis to a great extent. Gabrys-Barker (cf. 2006:145) proposes that the types of mistakes change over time depending on the proficiency level. Ringbom (2001:65), for example, proves that cross-linguistic influence based on the form of words is most common in the early period of language acquisition as researchers estimate that "vocabulary size (width) and organisation (depth) are first determined by formal language characteristics and not semantic ones". This suggests that, when beginning to learn a new language, lexical language transfer focuses rather on the form of words; and only later on when a certain language level has been achieved and semantics start to play a role in the lexical learning, CLI will also take place on a semantic level. Both categories of lexical competence, i.e. vocabulary size and vocabulary organisation, are advancing parallel to language proficiency. Therefore language proficiency plays an immense role in the occurrence and degree of lexical language transfer. 


\subsubsection{A Study on Lexical Transfer of Fixed Expressions}

The following study conducted by Cieslicka (cf. 2006:226-245) investigated how and to what extent the first language of a learner affects the comprehension and production of fixed expressions in the L2. Researchers differentiated between three types of idioms, namely lexical-level (LL)idioms, semi-lexical level (SLL) idioms and post-lexical level (PLL) idioms and examined if lexical transfer is more likely to occur in one than the others. The hypotheses were (1) that LL idioms should be the most facile to understand and produce, (2) that SLL idioms should show lexical transfer in the production but not in the comprehension part, and (3) that PLL idioms should be most difficult for learners both concerning production and comprehension. The two languages worked with were Polish and English. (cf. Cieslicka 2006:228).

The results of the study are that, first of all, correct answers decreased from LL to SLL and PLL indeed but the number of incorrect answers are very similar in the two categories LL and PLL (cf. Cieslicka 2006:239). This lack of a grave difference between LL and PLL idioms results might, firstly, speak for positive cross-linguistic transfer in LL idioms, which facilitate learning; and at the same time the outcomes imply that transfer is not likely to happen when there is a zero similarity relation between lexical items. Subjects admitted that acquiring PLL idioms was easy since they had just learned them off by heart. Therefore, there did not seem to be any (negative) influence of the L1, which was shown by the non-existent percentage of learners answering incorrectly with transfer (cf. Cieslicka 2006:239).

It was also observed that the learners gave the most wrong answers with language transfer on the SLL idioms questions. The production was, however, more concerned than the comprehension of SLL expressions. The results of the latter were even quite similar to those of LL idioms, i.e. a great amount of correct answers (cf. Cieslicka 2006:239).

As can be drawn from this study on lexical language transfer, the first language of a learner is a very important factor and maybe even a predictor for the development and possible achievement in second language acquisition. 


\subsection{Phonetic and Phonological Transfer}

Second language phonology and phonetics are one of the central research topics in transfer studies. This is because the mother tongue has an enormous influence on second language acquisition. The consequence of this unsuccessful phonological acquisition of a foreign language is commonly production errors in the second language speech (cf. Hansen 2006:8). It is widely known that numerous adult language learners have serious problems dealing with unknown languages; they do not seem to perceive speech the same way as young children do. Mehler et al. (cf. 1994 cited in Zhang and Wang 2007:150) and other researchers have investigated this foreign listening syndrome and have discovered a severe difference in the reception of sounds between children and adult learners: For adult learners it seems to be more difficult to identify and distinguish between sounds of a second language than of their mother tongue.

Concerning phonological transfer from L1 to L2, there are two common strategies learners use: Deletion and epenthesis (cf. Tarone 1980 in Hansen 2006:8). The former means that speakers delete sounds in their second language probably because that sound does not exist in their mother tongue and therefore they cannot pronounce it easily. Epenthesis, on the other hand, describes the process of inserting a sound into the word, which, again, makes it easier for the learner to pronounce it.

As discussed in chapter 6.2. Types of CLI there is both positive and negative crosslinguistic influence in second language acquisition. Major (cf. 1987 cited in Hansen 2006:9) observed that Japanese native speakers show both types of transfer when talking in their second language, English. Positive transfer occurred whenever the participants had to utter voiceless sounds in English; their pronunciation here was very accurate. This could be attributed to the fact that the participants were used to this sound feature as the Japanese language has many voiceless sounds, too. Negative transfer, on the other hand, was obvious in the production of consonant items which incorporated liquids (e.g. $l$ and $r$ ) compared to items without liquids. 


\subsubsection{Factors Influencing Phonetic and Phonological Transfer}

Through numerous studies on the influence of L1 on L2 phonology, one main factor that seems to influences the degree of phonological transfer has become apparent: Similarity. The already existing categorisation of L1 phonetics and phonology in the brain is used whenever speech is perceived (regardless if first or second language) and thus every sound is compared to the sounds of the L1 (cf. Perfetti et al. 2007 cited in Zhang and Wang 2007:150). The consequence of this discovery is that similarity is the influencing factor when it comes to transfer of phonology and phonetics. As Zhang and Wang (cf. 2007:151) summarise, not even high proficiency can totally extinct the accent due to similarity or lacking similarity (cf. e.g. Bosch, Costa and Sebastián-Gallés 2000).

The problem of similarity can be seen in the following study conducted by Sato in 1984 (cited in Hansen 2006:8). Vietnamese native speakers were tested on their correct syllable production in English. The participants had to pronounce words with two different types of syllables, namely open and closed ones. While open syllables end with a vowel, closed syllables have one or more consonants at the end. Clear evidence has been found that Vietnamese participants transferred linguistic knowledge from Vietnamese syllables to their second language English. First of all, it was obvious that the participants favoured closed syllables in comparison to open ones. Secondly, when consonants clusters stood at the end of a word they were uttered more accurately than when they were at the beginning of a word. These and other results of production accuracy of this study suggest language transfer from the first language to the second.

Flege and Davidian (cf. 1984 cited in Hansen 2006:9) discovered additional phonological transfers resulting from the similarity of languages. They examined the production of English final stops in Spanish, Polish and Mandarin Chinese subjects. They found that the first language of the participants had an enormous impact on stop deletion in the second one. Especially, those language learners who spoke Mandarin Chinese or Spanish as a mother tongue were much more likely to delete stops in the test. The reason for that was that there are no final stops in these two languages. 
Generally it can be said that second language speakers seem to make mistakes in pronunciation mainly because of first language transfer. In his study, Hodne (cf. 1985 in Hansen 2006:9)stated that 66 production errors (out of 666 word-final consonants) in English were located by Polish native speakers, of which 83 percent occurred because of L1 transfer. 


\section{The Influence of New Media on the Mother-}

\section{Tongue}

Since the internet was introduced a few decades ago, also everyday, i.e. non-online, language has changed significantly. It seems that especially English Netspeak has influenced the mother-tongues of millions of people. Yet, when did the internet become a new medium for language and how did it turn into such an important resource for non-online language? These questions will be answered in the following chapter.

\subsection{Netspeak: A New Language?}

While for written, spoken and sign language clear linguistic features can be defined, explaining internet language is slightly more complex. It has to be investigated if netspeak shares characteristics with spoken and/or written language and, more importantly, what is unique about this rather new variety.

To be able to draw a comparison between written and spoken language, the most important attributes of speech and writing are illustrated in the chart below:

\begin{tabular}{|l|l|}
\hline \multicolumn{1}{|c|}{ Speech } & \multicolumn{1}{|c|}{ Writing } \\
\hline Directly linked to time & Directly linked to place \\
\hline Dynamic and transient & Static and permanent \\
\hline Specific addressee & Unknown readers \\
\hline Sender and receiver are present & Receiver is not present \\
\hline Production and reception are at the same time & Production and reception are at different times \\
\hline No time for complex planning & Time for planning \\
\hline $\begin{array}{l}\text { Sentences divided into parts by intonation but } \\
\text { sentence boundaries often unclear }\end{array}$ & $\begin{array}{l}\text { Complex sentence structure (identifiable through } \\
\text { punctuation and layout) }\end{array}$ \\
\hline Gesture and mimic & No visual aid \\
\hline
\end{tabular}




\begin{tabular}{|l|l|}
\hline Deictic expressions (e.g. this one) & No deictic expressions \\
\hline Social function $\rightarrow$ relationships, attitudes & Stating facts, ideas \\
\hline $\begin{array}{l}\text { Non-correctable as the utterance has been heard } \\
\text { by the receiver once it has been said }\end{array}$ & Correctable \\
\hline Loudness, tempo, rhythm, pause & Pages, lines, capitalisation, punctuation \\
\hline
\end{tabular}

Table 1. Attributes of Speech and Writing

(cf. Crystal 2011:17-19)

When comparing internet language to written and spoken language, it also has to be considered that there is a large number of different forms of internet texts such as instant messages, blogs and social networks, which vary in their (dis)similarity to writing and speaking. The web language can sometimes even be fairly similar if not identical to written language when, for instance, books are copied and put on the internet. Another example are articles from journalists, which are often not changed but simply uploaded onto a homepage and therefore are either very close or even identical to written language (cf. Crytal 2011:20).

With emails and instant messages it is slightly different as, although they are written down, they share more characteristics with speech than with writing. Some of those applications such as Skype even allow the participants to see each other; for this reason it could be believed that Skype belongs entirely to the category of spoken language; however, there is still the problem of time delay between sending the message and receiving it, which is an essential characteristic of speech (cf. Crystal 2011:20).

According to Crystal (2011:21) netspeak, in general, "is better seen as writing which has been pulled some way in the direction of speech rather than as speech which has been written down". He also claims that it cannot be entirely attributed to spoken OR written language, as it shows significant characteristics of both. Furthermore, internet language makes use of additional linguistic features which none of the mentioned mediums possess (cf. Crystal 2011:21).

To begin with the comparison of internet language to spoken language, three main differences can be observed, which refer to simultaneous feedback, emoticons and multiple conversations. In normal speech participants can easily give each other simultaneous feedback. This is important because for a speaker this helps him or her to adapt language 
appropriately. Such feedback can be as simple as $\mathrm{mhm}$, what do you mean by that? or simply laughing or looking angry. In netspeak this simultaneous feedback does not exist, mainly due to the lag of time. The addresser of an Email, for example, does not receive immediate but deferred feedback, which is given too late to be used for modifying the original Email. Linguists argue that the absence of this important feature is responsible for the general opinion that some internet conversations are plainly rigid and reserved (cf. Crystal 2011:2123).

Gestures, mimics and body posture, which are essential for talking about opinions and attitudes and thus for maintaining relationships, are further linguistic items which the internet language lacks due to its non-existing proximity. Internet users try to compensate this lack by using emoticons, which are supposed to give additional information to a message (cf. Crystal 2011:23). However, emoticons are not always easy to interpret as often smilies such as ;) or $: D$ have more than one meaning $(;)=$ cheeky, flirty, agreeing; $: \mathrm{D}=$ laughing with you, laughing at you, being happy, being cheeky). New emoticons are permanently added to the internet language and there is one for almost everything as can be seen by means of this one " $\left(8^{\wedge}(\mid) "\right.$, which illustrates Homer Simpson from The Simpsons. As can be perfectly seen in this example, emoticons can often not be interpreted without their accompanying context (ibid).

The third difference, multiple conversations, are simply impossible in spoken language. We cannot concentrate on more than one or two people simultaneously in the real world. In a chat room, however, it is quite normal for members to talk to several people at the same time, which means that they not only receive messages but also answer them. It has not been detected yet why and how people are able to maintain several conversations at a time; it was investigated that short sentences, abbreviations and punctuation avoidance are indeed common features of chat room language but that also a number of complex sentences are commonly used (cf. Crystal 2011:24-25).

To continue with the linguistic features of written language which differ in internet language, the following three concepts need to be considered: Hypertext links, persistence and multiple authorship. The internet is basically a gigantic network that links computers to each other, which, in turn, allows users to exchange messages between their computers. In common written language this feature exists to some extent and can be seen in footnote numbers, cross-references and the bibliography if they are used by the author. The internet easily interconnects everything that is online(cf. Crystal 2011:28). 
Persistence means that once language is written down and published, its content cannot be changed anymore. Online language, on the other hand, can always be modified as can be seen in online articles which can be refreshed after having been uploaded. Even the whole layout and form of internet language can change suddenly when, for example, a window containing advertisements pops up on the screen (cf. Crystal 2011:29-30). For this reason, internet language is considered very flexible, which can sometimes be a problem as is shown in the following paragraph about multiple authorship.

Creating a text which contains the ideas of different authors on the same topic can be a problem if values and attitudes on the topic differ from author to author. Wikipedia, "the free encyclopaedia that anyone can edit" (Wikipedia Main Page), is a prime example for multiple authorship on the internet; the topics religion and politics, for example, are highly critical issues, which are dealt with very differently by every person. This makes it rather difficult for authors to contribute to a text without being biased. In addition, language barriers are an issue and, of course, the question of the reliability of the content arises (cf. Crystal 2011:31).

It can be concluded, that internet language does share some linguistic characteristics with speech and written language but it also holds a list of its own, very unique features.

\subsection{The Influence of the Internet Language Lexicon on Users' Everyday Language}

Several researchers have dealt with the question How much have internet users been influenced by internet jargon? since the internet was invented. Compared to ordinary language, internet language items have the potential of becoming known all over the world within minutes. However, is it really that easy for netspeak jargon to stay in people's minds and keyboards? According to Crystal (cf. 2011:57), it is not. Quite the contrary, it seems that only very few new words created by or on the internet actually are introduced into our normal, everyday language. Nevertheless, Crystal (cf. 2011:57-58) admits that there is an impact of the internet on normal written and spoken language to some extent, especially on vocabulary. 
Internet words that now seem to occur in the everyday language have originated from three main word formation processes, namely neologisms, acronyms and blends (cf. Crystal 2011:58-61). Bauer (cf. 1983:42-44, 234, 237-38) gives clear explanations of these three types of word formation processes. Neologism or Coinage means that words are coined from the very scratch. Brand names which are also used as a term for objects from other brands often belong in this category. A typical Coinage would for example be hoover for vacuum cleaner.

An acronym is a word which is built with the first letters of certain words. Often such words are easy to pronounce and can thus simply be uttered as a new word. Some general examples are REM (rapid eye movement), BBC (British Broadcasting Cooperation) and SALT (strategic arms limitation talks). Many acronyms, however, lost their capital letters and are simply spelled like any other words, like basic (beginners' all-purpose symbolic instruction code) and VAT (value added tax) (cf. Bauer 1983:237-38).

The third category of word formation is called blending and describes a word that is the result of the combination of two different words. Usually the front part of one word is parted with the end part of another (cf. Bauer 1983:234). Typical examples are brunch $($ breakfast + lunch $)$ and smog $($ smoke + fog $)$.

\subsubsection{Studies on Netspeak Usage}

Crystal (cf. 2011:58-61) describes the influence of Twitter language, blogging jargon and general netspeak. In 2010, which was four years after Twitter had been founded, 600 neologisms were collected in Twittonary, the Twitter online dictionary. Amongst them were a large number of wordplays starting with the element $t w$ - such as twictionary, tweologism, twafficandtwissues. Common blends were, for example, twitterholic, twitterhea and celebritweet (ibid:59). Forecasting which new words would anchor in the everyday language was impossible but at the end of this chapter I will investigate a few general acronyms by means of the corpus of contemporary British and American English.

Blogging has been practised much longer than Twitter since it was already established in 1994. The term blog (originally webblog) itself is a coinage and was created by John 
Barger in 1997 (cf. Farah et al. 2011). Many blends were created in blog language such as blargon for blog jargon, blogathy for blog apathy, blogorrhea for blog diarrhea, blogoholic for blog and alcoholic, and blogstipation for blog and constipation (cf. Crystal 2011:59).

Lexical transfers from general netspeak to normal language are for example the acronyms URL and FAQ which are pronounced as actual words and not just as single letters (cf. Crystal 2011:60). There is also a number of items which have been taken out of their technical context and are now used in everyday situations. He's studying, so he'll be offline for the next few hours is a typical example for this as the word offline in this context is not used to describe his absence of a chat room or anything else having to do with the internet (cf. ibid:61). Another very popular, according to Crystal (2011:61) even the "most widespread English", word originally coming from the internet is the abbreviation $L O L$ which means laughing out loud. It is both uttered as an acronym [el o: el] and as a word [lol].

Crystal (2011:60) concludes that "the internet is lexically highly active and rapidly changing". Still, he argues, merely a few thousand of those new words have established themselves in the everyday language of people.

Another way of investigating the use of internet language in different kinds of texts is the Corpus of Contemporary American English. This specific corpus is a collection of 450 million words taken from spoken and written texts. TTYL and LMAO are two of the more rare acronyms with their 1 and 2 hits out of 450 million, as can be seen in the comparison to one of the most common words the, which occurs 25063954 times in the corpus. Other, a slightly more frequent acronyms are $B T W$ (23 hits) and LOL (81 hits). Among the most widely known acronyms of internet language, $F Y I$ is the most frequent one, according to the Corpus of Contemporary American English; it appears 383 times in the corpus' vast collection of written and spoken texts. However, the word google, both used as a verb and as a noun seems to be, by far, the most frequently used word of internet language with 5579 hits in total (cf. Davies 1990-2008, The Corpus of Contemporary American English, online). 


\section{Empirical Research: Investigating Phonological, Phonetic and Lexical Transfer}

After having elaborated theory and interesting research on cross-linguistic influence, I wanted to conduct my own study on phonological, phonetic and lexical transfer. For Austrian people, especially for pupils, it is quite normal to know more languages than just their mother-tongue. This is either due to school education or simply self-motivation. For me as a teacher, it seemed particularly interesting to find out about language transfer in school contexts. For this reason, two expert teachers of different schools were interviewed on their experience with students' language. The interview questions focused on phonological, phonetic and lexical transfer. The purpose of this study was to learn more about how the first language, i.e. German in this case, interferes with the classroom language English, and what can be done to prevent or reduce this transfer.

In addition, as internet language is a rather new or modern phenomenon, I also wanted to examine the influence of English internet language on the use of the mother-tongue (German) of beginners and advanced English learners. It seemed highly interesting to find out how much impact this very different variety of the English language actually has on today's younger and older teenagers' everyday language in Austria.

\subsection{Semi-Structured Interviews}

Conducting two semi-structured interviews appeared most suitable for the research goal of this study as open questions were essential and spontaneous follow-up questions contributed to extensive data about phonological, phonetic and lexical transfer of pupils. Firstly, the influence of the first language German on the phonological and phonetic output of the second language English was examined. Common pronunciation mistakes made by students were specified and analysed according to the students' level of English and other relevant factors such as amount of language input. The second part of the interview was concerned with lexical transfer. It was investigated to what extent the mother-tongue of Austrian children and teenagers influences their lexis use in English. In particular, I wanted to find out if there are 
typical lexical transfers made by German native-speakers and if so, if there is a crucial difference between language learners with basic proficiency skills in English compared to those with high proficiency skills.

\subsubsection{Participants}

The first teacher who was interviewed on phonological, phonetic and lexical transfer of students is female and has been teaching English, Psychology and Philosophy for over 20 years now. This means that her language proficiency level in English is very high, which rendered her an ideal interview partner for this research topic. In my study findings, I will refer to her as teacher $A$.

The school she teaches at is a bilingual, international secondary school (approximately age 10 to 19), namely the GIBS, where all subjects and also lesson-external conversations are held in English. I chose this school on purpose as it could be expected that there is a significant difference between language transfer of students of a bilingual school and an ordinary one. What has to be mentioned, however, is that, contrary to expectations, applicants for the GIBS do not have to pass an English language test but a general entrance examination dealing with intelligence and social skills. This seems to eliminate aptitude as an influencing factor at least to some extent. While it is clear that many of the applicants are not only very interested in the English language but also show a certain talent for the language, this cannot be generalised. In either case, once admitted to the school, the children's English proficiency will, of course, increase faster than that of a child in a secondary school where classes are held in German. This is why special focus will be given to the differences of the two teachers' answers in the interview.

The second teacher who was willing to take part in an interview about phonological, phonetic and lexical transfer has also been working as a teacher for almost 20 years. Her school subjects are English and Geography and she teaches English in both lower and higher grades, which made her a suitable interviewee for this study. She works at the private school Bischöfliches Gymnasium (students are between 10 and 19 years old), which could be an important factor as private schools are sometimes said to offer better education than other schools. In terms of the English language, the Bischöfliches Gymnasium is a normal 
secondary school having ordinary English classes but no other classes taught in English. To her, I will refer as teacher $B$.

\subsection{Questionnaire}

For finding out if English netspeak has any influence on the general linguistic usage of Austrian children and teenagers, a student questionnaire seemed most suitable.

\subsubsection{Participants}

The study was carried out in the private secondary school Bischöfliches Gymnasium in Graz and included one lower and one upper grade. The questionnaire was filled in by a third form and a seventh form. In the former there were 13 girls and seven boys aged between 12 and 14 years. They have been learning English for two and a half years in school.

The second group, i.e. the seventh grade, consisted of 23 pupils aged from 16 to 17 , who have been participating in English classes in school for six and a half years. Their class is made up of eleven boys and twelve girls. The two grades (being very different in their language proficiency level) were chosen due to the fact that I was interested if English internet language influences beginners and advanced learners somehow differently.

\subsection{Phonological, Phonetic and Lexical Transfer From German to English: Two Teacher Interviews}

In the following chapter the questions used in the teacher interviews are explained and examined for their relevance to the research questions. The interview questions for the two teachers were divided into two parts, namely phonological and phonetic transfer and lexical 
transfer. The first part deals with the interference between German sounds and sound patterns and the English language and looks like this:

\section{Phonological and Phonetic Transfer}

1. Can you give examples of sounds (sound patterns, intonation problems,..) beginners often pronounce incorrectly?

2. Can you give examples of sounds (sound patterns, intonation problems,..) advanced students often pronounce incorrectly

3. Why do you think these mistakes occur?

4. Can you see if/where mispronunciation is coming from German transfer?

5. Have you experienced any case where it was really difficult to get rid of a student's accent? [If so, what was the problem? What happened?]

6. How do you address/correct such problems? Can you give specific examples? (Exercises,..)

With the first two questions I wanted to find out if there were any typical sounds, sound patterns or intonation problems that student often encountered. While question number 1 was concerned with the beginners' mistakes, question number 2 focused on more advanced students. The teachers were asked about the groups in two separate questions so that they could really think about the differences between the groups. Of course it was to be expected that younger learners face difficulties with new sounds more often; what I was very interested in, however, was the question if the type of pronunciation mistakes differed between beginners and more sophisticated students. This I wanted to find out with questions number 1 and 2.

The third question was supposed to explore the opinion of the teachers why they think such mistakes occur in the class room. As I did not know what they would answer, if they would give cross-linguistic influence as a reason, I explicitly asked them in question number 
4 if they believed that mispronunciation derived from German transfer; and if yes, which common mistakes they could detect.

The fifth and sixth question on phonological and phonetic language transfer seemed very valuable for me as a future teacher. I wanted to find out if the teachers could recall particular cases of students who simply could or could not get rid of certain pronunciation mistakes. Subsequently, the teachers were asked how they addressed such problems and if they had any exercises for students to deal with phonological and phonetic transfer from German and to consequently get rid of such pronunciation mistakes.

The questions of the second part of the interview, about lexical transfer in school contexts are similar to the ones in the first part and look like this:

\section{Lexical Transfer}

7. What are typical words or phrases (structures,..) beginners tend to transfer from German to English?

8. What are typical words or phrases (structures,..) advanced students tend to transfer from German to English?

9. How much of a problem is lexical transfer for older students?

10. If it is more/less problematic for them, why do you think this is the case?

11. Do students transfer more/less/different in written and spoken language? If yes, how? Why, do you think, this is the case?

12. How do you address/correct such mistakes? Are there any exercises you use? (Reading,...?)

In question number 7 and 8 , the teachers were asked directly for words, phrases or other morphological structures beginners and advanced students seem to transfer from German to 
English. Again, an intentional distinction was made between transfer of beginning language learners and learners already having achieved a higher English proficiency level.

To explore the differences between the two groups of students more thoroughly, question number 9 explicitly asks how much of a problem lexical transfer is for those students with higher proficiency level. Subsequently the follow-up question number 10 deals with the reasons why it could be more/less problematic for older students. I wanted to know what teachers thought, why advanced pupils transferred differently to beginners, if it only had to do with proficiency level or if there were other relevant factor too.

Another aspect I definitely thought was highly interesting was the question if language transfer played a different role in written and spoken language or if it was more or less the same. The teachers were encouraged to share their long-time experience on this subject and to think about the different situations in which language transfers occurred.

The last question was the same as in the phonological and phonetics part, only based on lexis. It tried to detect several ways of handling lexical transfer in school and possible exercises to minimise such mistakes. 


\subsubsection{Results}

Beginning with sounds and sound patterns students typically pronounce wrongly, it can be said that teacher A has not noticed great differences between beginners and advanced English learners. She rather thinks that if younger students pronounce certain sounds incorrectly, they will have difficulties with the same sounds in higher grades, and not suddenly with other sounds. It is unlikely for learners to pick up mispronunciation later on when they are already on a higher level of English. A typical sound that students seem to have difficulties with is th like in they; it is often pronounced like an $f(/ \mathrm{feI} /$ for /ðeI/) or $s$ (/seI/ for /ðeI/).Another major field are the voiced and devoiced sounds in general such as $p$ and $b$, and $t$ and $d$, which are all pronounced the same, i.e. voiced. The sound $æ$, as in the word apple, also creates problems for many students.

Teacher B agrees with teacher A that no new pronunciation mistakes are picked up when learners reach a higher level of English. She also states that voiced and unvoiced sounds such as / /in George and /t / in church are often pronounced incorrectly by mixing them up. $/ \mathrm{P} /$ and $/ \mathrm{b} /$ and $/ \mathrm{t} /$ and $/ \mathrm{d} /$ are often all uttered as the voiced sounds $/ \mathrm{b} /$ and $/ \mathrm{d} /$. Another problem appears to be the English /v/ like in vase; pupils tend to confuse /v/ and /w/ like in very and water and use $/ \mathrm{w} /$ instead of $/ \mathrm{v} /$. One problem specifically noticed in advanced students are, according to teacher B, sentence intonation problems. Sentences and phrases are pronounced very monotonously and punctuation marks are often ignored. There is no rising and falling of the pitch in some students' reading and speaking.

Continuing with the reasons of pronunciation errors, teacher A clearly defines linguistic transfer as the obvious origin of such mistakes. She says that pupils simply try to apply the sound system that they already know, i.e. the German sound system, to the English language. This, however, often does not work as the sounds are different in these two languages. In addition, teacher A thinks that language aptitude is an important factor in second language learning and that it facilitates phonological and phonetic learning.

Teacher B also names German transfer as the main reason for wrong pronunciation as German sounds are pronounced differently to English sounds. She mentions a very interesting aspect of transfer when she says that sometimes "not-having-it" in German pronunciation also makes it difficult for learners to pronounce the English sound correctly. As they do not have any linguistic knowledge of particular English sounds, they try to pronounce it as which seems to be the most similar sound to them in German. Summed up, teacher B says that the 
lack of knowledge of the English sound system determines the phonological transfer from German to English.

Another influence, which both teachers address, is the sense of hearing. They believe that many of the students do not have a sensitive ear to what sounds sound like and this of course renders it problematic when they have to repeat and practise sounds. According to teacher A, pupils who play a musical instrument are able to differentiate between sounds more easily and therefore achieve a better pronunciation than non-musical language learners.

When I asked the teachers whether they could remember a case where a student had severe difficulties with English pronunciation they could not recall a specific one. Both teachers said that pronunciation mistakes do not seem to be such a big deal for students. Of course they make mistakes and sometimes they take longer to get rid of them whereas in other cases the problems are solved immediately after telling them. In general, however, the students' pronunciation develops and improves quickly.

In terms of correcting pronunciation mistakes, teacher A uses co-teachers, who are native-speakers of English, to give students a lot of input. Teacher B requires pupils to read aloud in class and not only one sentence but whole passages so that they can practise not only sounds but also sound patterns and sentence intonation. For voiced and devoiced sounds, she asks pupils to practise the sounds and touch their throat to really feel the difference between the two types of sounds.

The second part of the interview, about lexical transfer, was extremely informative too. Teacher A generally observes that the lower the level of English is the more likely lexical transfer occurs in her school. She attributes this to the great input students get during their time in school and to the several stays abroad during this time. A typical specific word beginners use incorrectly is become for get/receive as in the example Look, I became an Easter egg!. In addition, younger learners tend to transfer the German word order and produce samples like then went $I$ as it is dann ging ich in German. Advanced students also transfer German words to the English language such as on the picture instead of the right version in the picture. Another common mistake is that pupils say an example for something instead of an example of something. Prepositions, on the whole, seem to be one of the main problems in lexical transfer for both beginners and advanced students, according to teacher A. Another issue for both learner groups is the length and complexity of sentences. Many students produce incredibly long sentences by using numerous and's, but's and because's, because they 
are used to doing this in the German language. In English, however, sentences are supposed to be rather short and do not contain a lot of subordinate clauses.

Teacher B finds that the younger language learners are the more light-hearted when it comes to guessing the meaning of words. She also says, however, that, in her opinion, more advanced language learners have more difficulties with lexical transfer from German to English than the beginners. The more extensive the vocabulary gets the more likely it is for students to be influenced by their mother-tongue. She explains this as follows: Having a high level of English means that students know many different meanings of words and their different possible areas of application. This, in turn, seems to confuse pupils and makes them draw on their lexical knowledge from the German language to cope with this insecurity. Teacher B recalls one specific lexical error pupils tend to make, which is the wrong use of the word actual. Students often say and write the word actual when they want to refer to the German word aktuell, which, however, equals the English word current and not actual. In general, teacher B, agrees with teacher A that word order structures is one of the main problems of students as they often transfer the German word order to the English word order, which of course does not work as already explained in the previous paragraph. She observes that it takes quite a while for students to get used to the manner-place-time structure of the English language.

Discussing a possible difference in written and spoken language, both teacher A and teacher B have the feeling that there is more lexical transfer in written than in spoken language. Teacher A says that this is the case because students cannot imitate (for example from their teacher) as much in their written work compared to their oral language. Writing a text means producing something very specific, which does not allow pupils to imitate a lot of what they have heard or read so far; writing demands more autonomous thinking than speaking. Writing a text thus takes some time and, according to teacher A, most pupils want to use sophisticated structures and phrases, which they, however, often do not know how to use and therefore transfer German structures to their English texts. With speaking, on the other hand, teacher B explains, there is more spontaneity, which, in turn, does not give enough room for German transfer. Either students do not have the time to think about their mother tongue at the same time when they are talking in English or they simply describe the words they cannot think of at that moment, which is an easy and quick strategy in spoken language. 
Exercise-wise, the teachers agree again when they say they try to not explicitly give the wrong words that could create problems, but rather work prophylactically. Giving students great input seems to be the best way to prevent them from transferring German words to the English language. Students should read in English a lot, as they can learn so many words from books, teacher A says. When lexical transfer occurs in class, the teachers correct it informally and do not point out the German influence too much. When several students make the same mistakes in their texts and/or speaking, the teachers do show them a list with the wrong words (coming from German transfer) and the correct words on it but do not give them the sheet. They only let them note down the correct version of the words. Both teachers find it important to not give them the visual input of the German influences, so that they cannot imprint the wrong words on their memory.

According to teacher B it is far more important for both the teachers and the students that the students know how to communicate successfully instead of desperately trying to avoid making mistakes. All in all, teacher A and B agree, students learn English in order to communicate with it. 


\subsection{Transfer from Netspeak of the Second Language English to the Mother-tongue German: A Student Questionnaire}

In the following chapter the questions of the student questionnaire are presented and analysed in terms of their relevance to the study question, i.e. if English internet language influences students' everyday use of their native language. In addition, information is given on several other aspects of the study such as the piloting, duration and anonymity.

First of all, the questionnaire contained two factual questions right at the beginning where students' had to state their age and gender. This was important as investigating the difference between younger and older students was one of the main general goals of this study. In addition to the age factor, it seemed interesting to also compare boys and girls with each other.

The questionnaire consisted of five main questions which scanned the students' use of netspeak, but also their knowledge about this variety. All instructions were given in English and German as misunderstandings, especially amongst the beginners should be avoided.

The first question concerned with internet language was a multiple choice question. Its purpose was to find out which of the suggested internet language items students had heard of or read before. All study questions dealt with the same 16 netspeak items, i.e. googeln (to look something up on the internet), PLS (please), OMG (oh my god), TBT (truth be told, throwback Thursday), THX (thanks), LOL (laughing out loud), ${ }^{*} G G^{*}$ (grins grins, giggle giggle), TTYL (talk to you later), G2G (got to go), ROFL (rolling on the floor laughing), BTW (by the way), CU (see you), FYI (for your information), XO (kiss and hug), LMAO (laughing my ass off) and $I<3 U$ (I love you). I deliberately chose both elements which seem to be quite common in Austria and items which I have not heard of or seen very often in German speaking countries. Students could also add items in the "other: " section if they felt items were missing in the list. 
1. Which of the following English Netspeak elements have you heard of or read before? Please tick the boxes.

[Von welchen der folgenden Internetausdrücken hast du schon einmal gehört?]

$\begin{array}{llll}\text { googeln } & \text { THX } & \text { G2G } & \text { FYI } \\ \text { PLS } & \text { LOL } & \text { ROFL } & \text { XO } \\ \text { OMG } & { }^{*} \text { GG* } & \text { BTW } & \text { LMAO } \\ \text { TBT } & \text { TTYL } & \text { CU } & \text { I }<3 \mathrm{U}\end{array}$

In question number two the same choice of netspeak elements was given, yet this time students had to provide information of their use of these elements. They were asked which of the English items they had already used in their German writing or speaking. Again, they could also write down items that they had already used but which were not on the ready-made list.

2. Which of the following English Netspeak elements have you used in your German writing or speaking? Please tick the boxes.

[Welche der Ausdrücke hast du schon einmal in deutscher schriftlicher oder mündlicher Sprache verwendet?]

$\begin{array}{llll}\text { googeln } & \text { THX } & \text { G2G } & \text { FYI } \\ \text { PLS } & \text { LOL } & \text { ROFL } & \text { XO } \\ \text { OMG } & { }^{*} \text { GG* } & \text { BTW } & \text { LMAO } \\ \text { TBT } & \text { TTYL } & \text { CU } & \text { I }<3 \mathrm{U}\end{array}$

In the third part of the questionnaire, pupils had to rate a statement concerning the 16 internet language elements according to a Likert scale. They had to state to which extent they agreed with the statement I know how to use the following internet language items correctly in German. I decided to use a four answer model as it was less likely for students to simply chose the "middle answer" as a possible consequence of not wanting to engage further into the question. The four answers that could be circled were Strongly disagree (1), Disagree (2), Agree (3) and Strongly agree (4). 
3. In this part we would like you to tell us how much you agree or disagree with the following statement by circling a number from 1 to 4 .

[Wie sehr trifft die Aussage über die folgenden Internetausdrücke auf dich zu?]

"I know how to use the following English Internet Language Items correctly in German."

["Ich weiß, wie man die folgenden Internetausdrücke richtig verwendet in deutschen Unterhaltungen."]

\section{Example:}

If you strongly agree that you know how to use "LOL", you do the following:

[Wenn es absolut zu trifft, dass du weißt, wie man "LOL" richtig verwendet, dann:]

\begin{tabular}{|l|l|l|l|l|}
\hline$L O L$ & 1 & 2 & 3 & (4) \\
\hline
\end{tabular}

\begin{tabular}{|c|c|c|c|c|}
\hline & $\begin{array}{c}\text { Strongly } \\
\text { disagree/ } \\
\text { Trifft gar nicht } \\
\text { zu }\end{array}$ & $\begin{array}{c}\text { Disagree/ } \\
\text { Trifft eher nicht } \\
\text { zu }\end{array}$ & $\begin{array}{c}\text { Agree/ } \\
\text { Trifft eher zu }\end{array}$ & $\begin{array}{l}\text { Strongly agree/ } \\
\text { Trifft absolut zu }\end{array}$ \\
\hline Googeln & 1 & 2 & 3 & 4 \\
\hline PLS & 1 & 2 & 3 & 4 \\
\hline OMG & 1 & 2 & 3 & 4 \\
\hline TBT & 1 & 2 & 3 & 4 \\
\hline THX & 1 & 2 & 3 & 4 \\
\hline LOL & 1 & 2 & 3 & 4 \\
\hline${ }^{*} \mathrm{GG}^{*}$ & 1 & 2 & 3 & 4 \\
\hline TTYL & 1 & 2 & 3 & 4 \\
\hline G2G & 1 & 2 & 3 & 4 \\
\hline ROFL & 1 & 2 & 3 & 4 \\
\hline BTW & 1 & 2 & 3 & 4 \\
\hline $\mathrm{CU}$ & 1 & 2 & 3 & 4 \\
\hline FYI & 1 & 2 & 3 & 4 \\
\hline XO & 1 & 2 & 3 & 4 \\
\hline LMAO & 1 & 2 & 3 & 4 \\
\hline$I<3 U$ & 1 & 2 & 3 & 4 \\
\hline
\end{tabular}

Table 2. Question 3 of the Student Questionnaire

With this question I wanted to examine if pupils knew how to use netspeak elements correctly in a German context. As I expected that most of the students knew how to use at least some of the elements, the next question (4) was particularly interesting. 
Compared to the other questions of this questionnaire, question number 4 tested students on their actual knowledge of internet language. I wanted to investigate if pupils even knew what the internet language items that they used mean, i.e. if they knew what the acronyms stand for. It seemed highly interesting to me to find out if pupils needed to know the exact words these acronyms stand for or if they simply use these elements as "new words" in adequate contexts without having to know what the single letters stand for. This open question looked as follows:

4. Please answer the questions by writing out the full words. If you do not know the answer, simply cross out the question like this "What does ".." stand for?".

[Für was stehen die folgenden Abkürzungen und Wörter in Englisch? Wenn du eine Antwort nicht weißt, streiche die Frage bitte durch.]

4.1. What does 'googeln' stand for?

4.2. What does 'PLS' stand for in English?

4.3. What does 'OMG' stand for in English?

4.4. What does 'TBT' stand for in English?

4.5. What does 'THX' stand for in English?

4.6. What does 'LOL' stand for in English?

4.7. What does '*GG"' stand for in English?

4.8. What does 'TTYL' stand for in English?

4.9. What does 'G2G' stand for in English?

4.10. What does 'ROFL' stand for in English?

4.11. What does 'BTW' stand for in English?

4.12. What does 'CU' stand for in English?

4.13. What does 'FYl' stand for in English?

4.14. What does 'XO' stand for in English?

4.15. What does 'LMAO' stand for? 
I explicitly asked pupils to cross out the questions which they did not know the answers to since if they had simply left these questions blank, it could have also meant that they had overlooked the questions.

Question number five focused on the German contexts in which pupils use internet language. I tried to find out if there is a general difference between spoken and written language and if they used different elements with different people in different situations. The two modes were separated in two tables:

\section{When do you use English Netspeak in German Writing and/or Speaking? Please circle your answers. You can circle as many answers as you need to. [Wann verwendest du die folgenden Ausdrücke in deutschen Unterhaltungen?]}

\subsection{Speaking}

\begin{tabular}{|l|l|l|l|l|}
\hline Googeln & Talking on the phone & Talking to friends & Talking to my parents & Never \\
\hline PLS & Talking on the phone & Talking to friends & Talking to my parents & Never \\
\hline OMG & Talking on the phone & Talking to friends & Talking to my parents & Never \\
\hline TBT & Talking on the phone & Talking to friends & Talking to my parents & Never \\
\hline THX & Talking on the phone & Talking to friends & Talking to my parents & Never \\
\hline LOL & Talking on the phone & Talking to friends & Talking to my parents & Never \\
\hline${ }^{*}$ GG* & Talking on the phone & Talking to friends & Talking to my parents & Never \\
\hline TTYL & Talking on the phone & Talking to friends & Talking to my parents & Never \\
\hline G2G & Talking on the phone & Talking to friends & Talking to my parents & Never \\
\hline ROFL & Talking on the phone & Talking to friends & Talking to my parents & Never \\
\hline BTW & Talking on the phone & Talking to friends & Talking to my parents & Never \\
\hline CU & Talking on the phone & Talking to friends & Talking to my parents & Never \\
\hline FYI & Talking on the phone & Talking to friends & Talking to my parents & Never \\
\hline XO & Talking on the phone & Talking to friends & Talking to my parents & Never \\
\hline LMAO & Talking on the phone & Talking to friends & Talking to my parents & Never \\
\hline I <3 U & Talking on the phone & Talking to friends & Talking to my parents & Never \\
\hline
\end{tabular}

Table 3. Question 5.1. of the Student Questionnaire 


\subsection{Writing}

\begin{tabular}{|c|c|c|c|c|}
\hline Googeln & WhatsApp & Facebook & SMS & Never \\
\hline PLS & WhatsApp & Facebook & SMS & Never \\
\hline OMG & WhatsApp & Facebook & SMS & Never \\
\hline TBT & WhatsApp & Facebook & SMS & Never \\
\hline THX & WhatsApp & Facebook & SMS & Never \\
\hline LOL & WhatsApp & Facebook & SMS & Never \\
\hline${ }^{\star} \mathbf{G G}{ }^{*}$ & WhatsApp & Facebook & SMS & Never \\
\hline TTYL & WhatsApp & Facebook & SMS & Never \\
\hline G2G & WhatsApp & Facebook & SMS & Never \\
\hline ROFL & WhatsApp & Facebook & SMS & Never \\
\hline BTW & WhatsApp & Facebook & SMS & Never \\
\hline CU & WhatsApp & Facebook & SMS & Never \\
\hline FYI & WhatsApp & Facebook & SMS & Never \\
\hline XO & WhatsApp & Facebook & SMS & Never \\
\hline LMAO & WhatsApp & Facebook & SMS & Never \\
\hline$I<3 U$ & WhatsApp & Facebook & SMS & Never \\
\hline
\end{tabular}

Table 4. Question 5.2. of the Student Questionnaire

A pilot study was conducted at the GIBS to find possible flaws or problems concerning instructions and duration. In general, it took the pupils between 8 and 13 minutes to fill in the questionnaire. They had no severe difficulties answering the questions and found the instructions very clear. There was one student who told me that he had used the likert scale in question 3 wrongly as he had circled 1 for strongly agree and 4 for strongly disagree. Apart from this difficulty, no other problems occurred.

In the actual study in the Bischöfliches Gymnasium neither the lower nor the upper grade had any problems filling in the questionnaire. It took both the third and the seventh grade exactly ten minutes to complete the questionnaire. Of course, anonymity was maintained in this study as students did not have to write their names on the sheets. 


\subsubsection{Results of the Third Grade}

The results of the questionnaire are illustrated in tables in order to make differences in the use of internet language items more obvious. The third grade's results are presented first and are organised according to the order of the questions in the questionnaire. In total, of 20 pupils, seven boys and 13 girls, participating in this study.

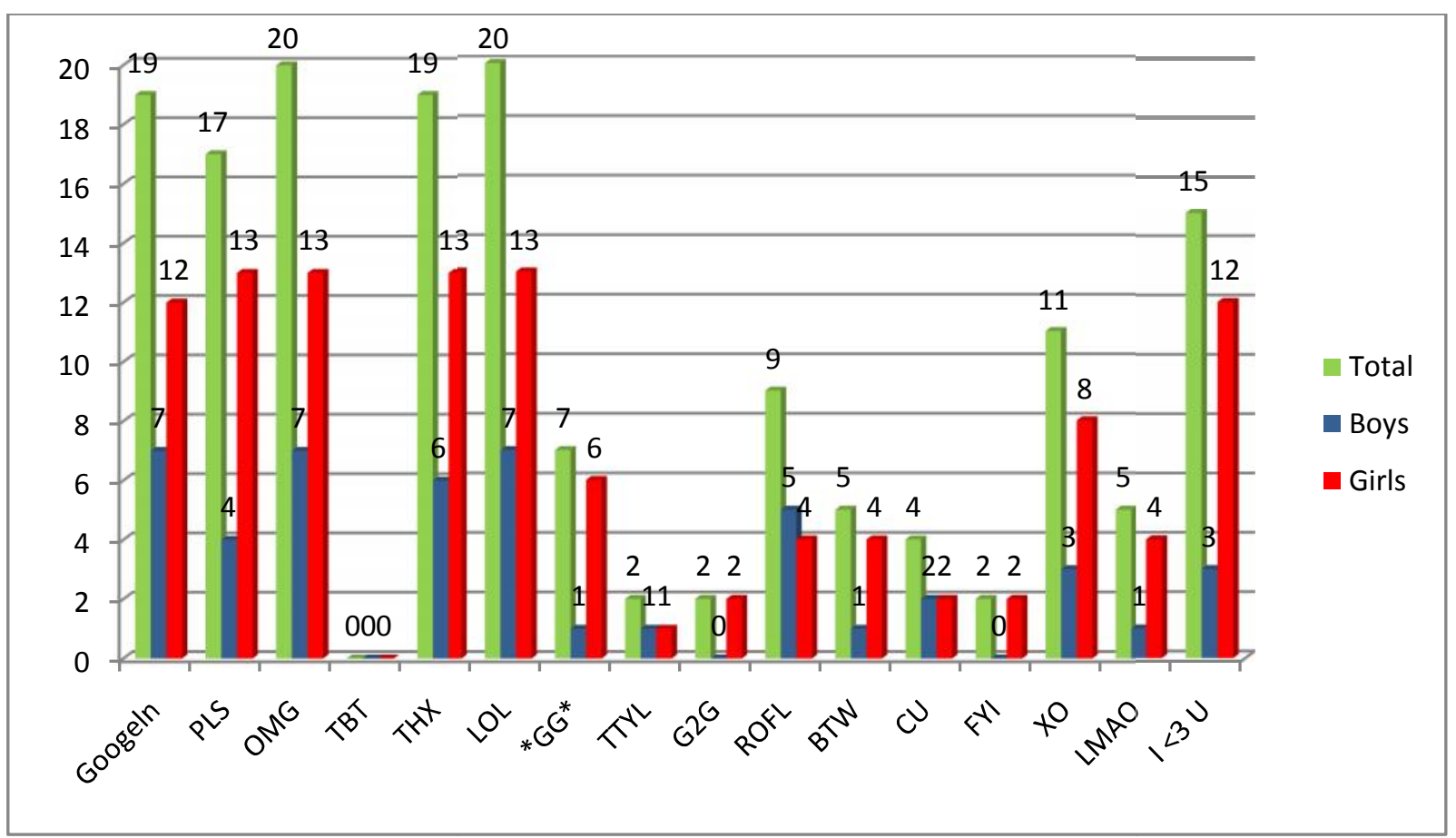

Table 5. Third Grade: Netspeak items students have heard of

Table 2 shows that the four items googeln, OMG, THX and $L O L$ were known by at least 95 percent of the subjects; OMG and LOL even by all of the participants. The majority of the students was also familiar with $P L S$ and $I<3 U$. When we distinguish between female and male subjects, however, it can be said that PLS was known by all of the girls but only by four (out of seven) boys. For $I<3 U$, the male percentage is even lower, i.e. three out of seven boys had heard of this item, whereas all girls except for one had heard of it. TBT, TTYL, G2G and FYI seem to be rather uncommon netspeak elements amongst these 12 to 14 year olds. 


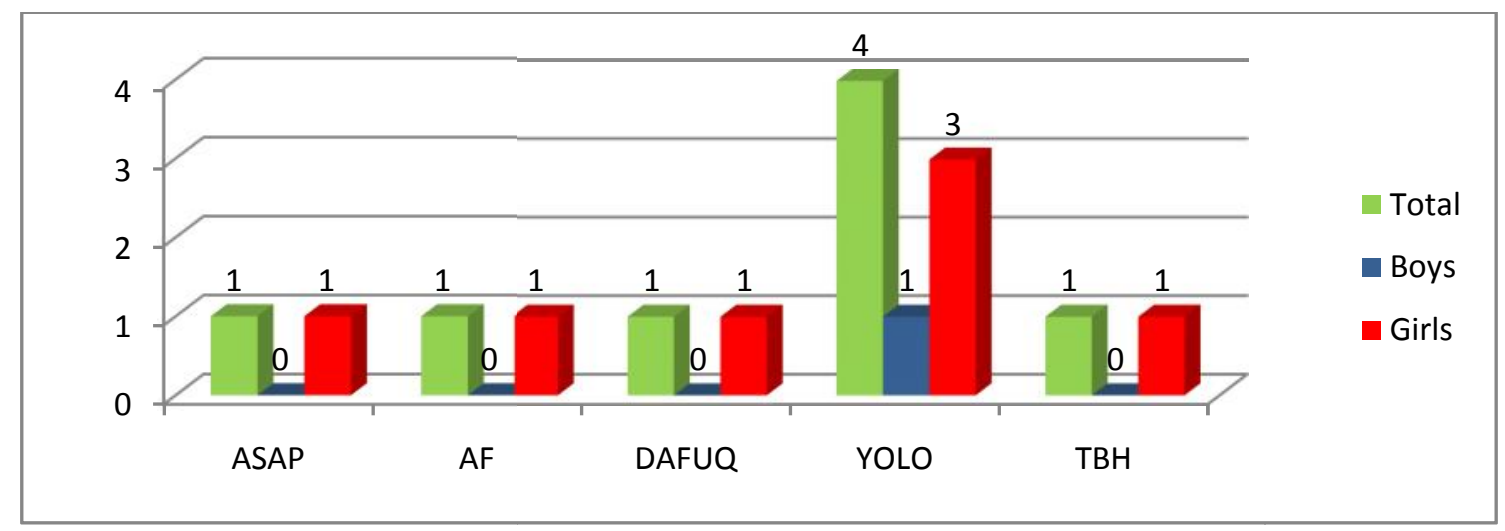

Table 6. Third Grade: Other netspeak items students have heard of

Amongst other netspeak elements, students added to the existing list, there was one which was mentioned four times, once by a boy and three times by girls, namely YOLO. YOLO stands for you only live once and seems to have become quite popular since it first came up only a few years ago. What was also observed is that some English students were familiar with internet swear language such as $A F$ (as fuck) and DAFUQ (what the fuck). 


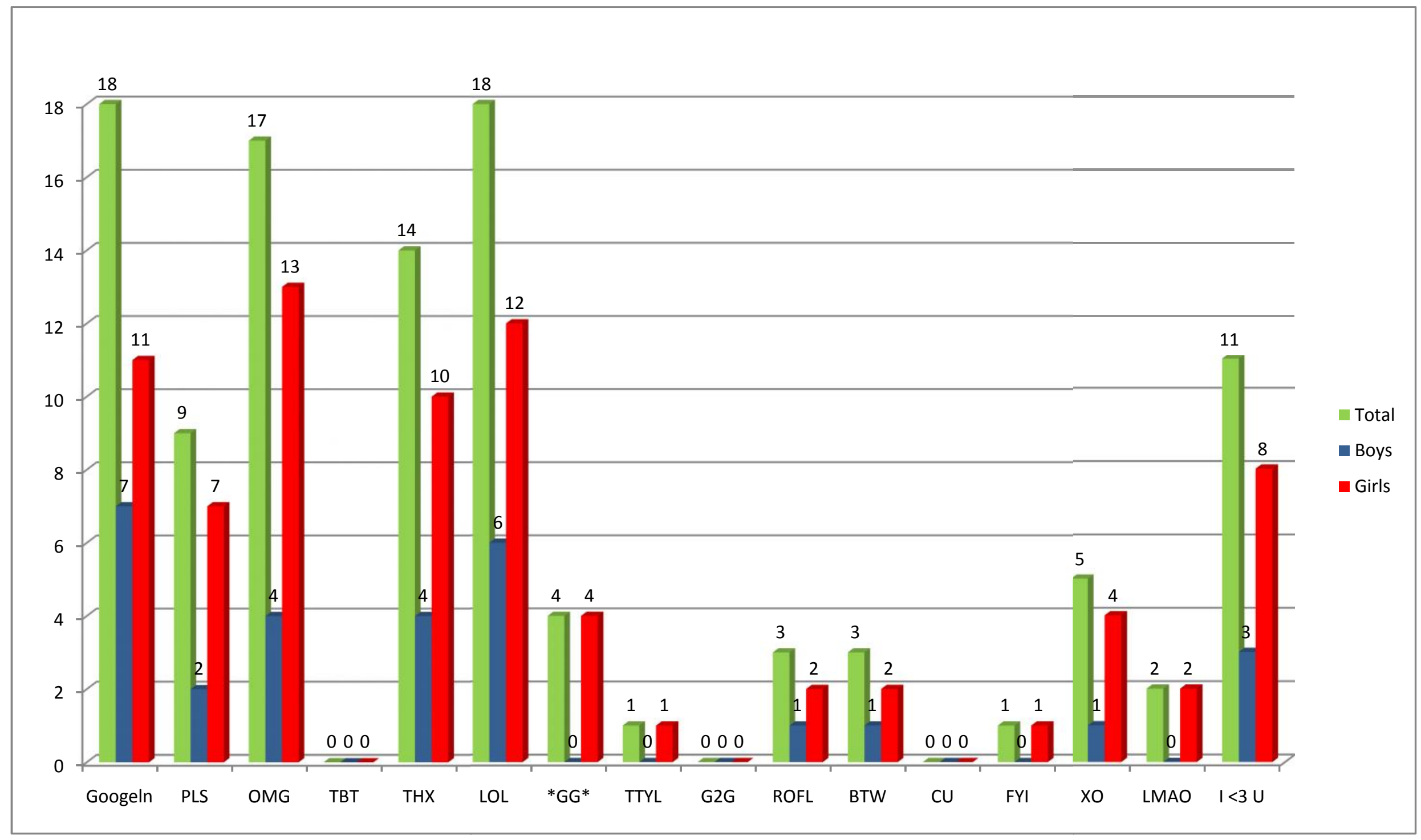

Table 7. Third Grade: Netspeak items students use in German writing or speaking 
When it comes to the question, which of the given netspeak elements third graders actually use in German conversations, the verb googeln and the acronym $L O L$ are without question the most frequent ones as can be seen in table 4. $O M G$ is ranked third and is used by all of the girls but only by half of the boys. In addition, students stated that they used $T H X$ and $I<3 U$ quite a lot. $T B T, G 2 G$, TTYL, $C U$ and $F Y I$ on the other hand, are only used by few students, which was to be expected as these items had only been known to very few or even none of the subjects. Interestingly, the counterpart of $T H X$, namely $P L S$, is not used as frequently as $T H X$. 


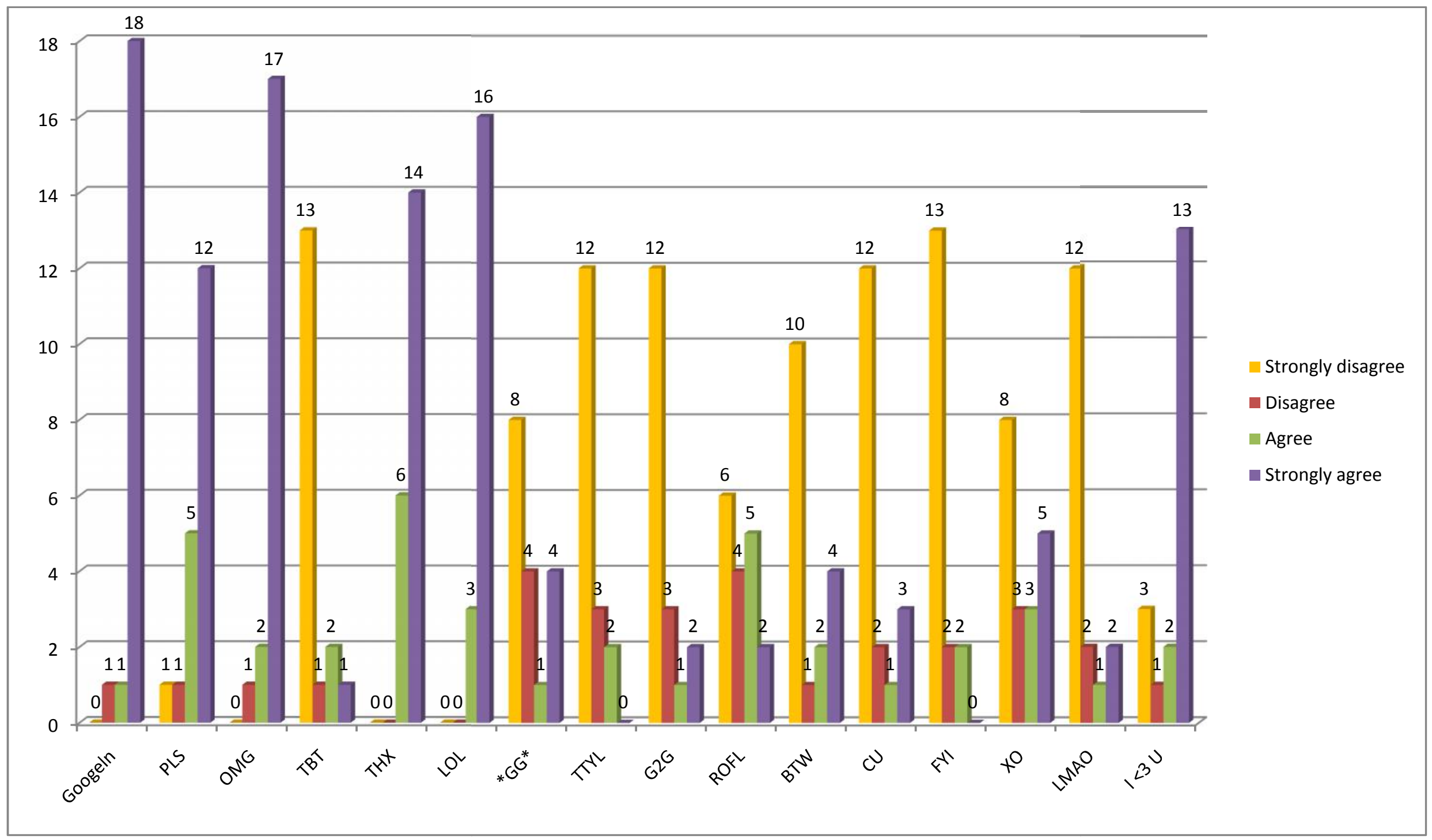

Table 8. Third Grade: Students know how to use these netspeak items in German writing or speaking 
In table 5, we can see that most of the students believe that they exactly know how to use googeln, OMG and LOL correctly in spoken and/or written German. PLS, THX and $I<3 U$ seem to be no problem either for the students as the majority claims they know how to use it in German contexts. However, they were not so sure about the rest of the internet language items. ROFL seems to be more or less clear to half of the students; for the remaining nine items, however, most of the students strongly disagree or disagree that they know how to use them correctly in spoken and/or written German.

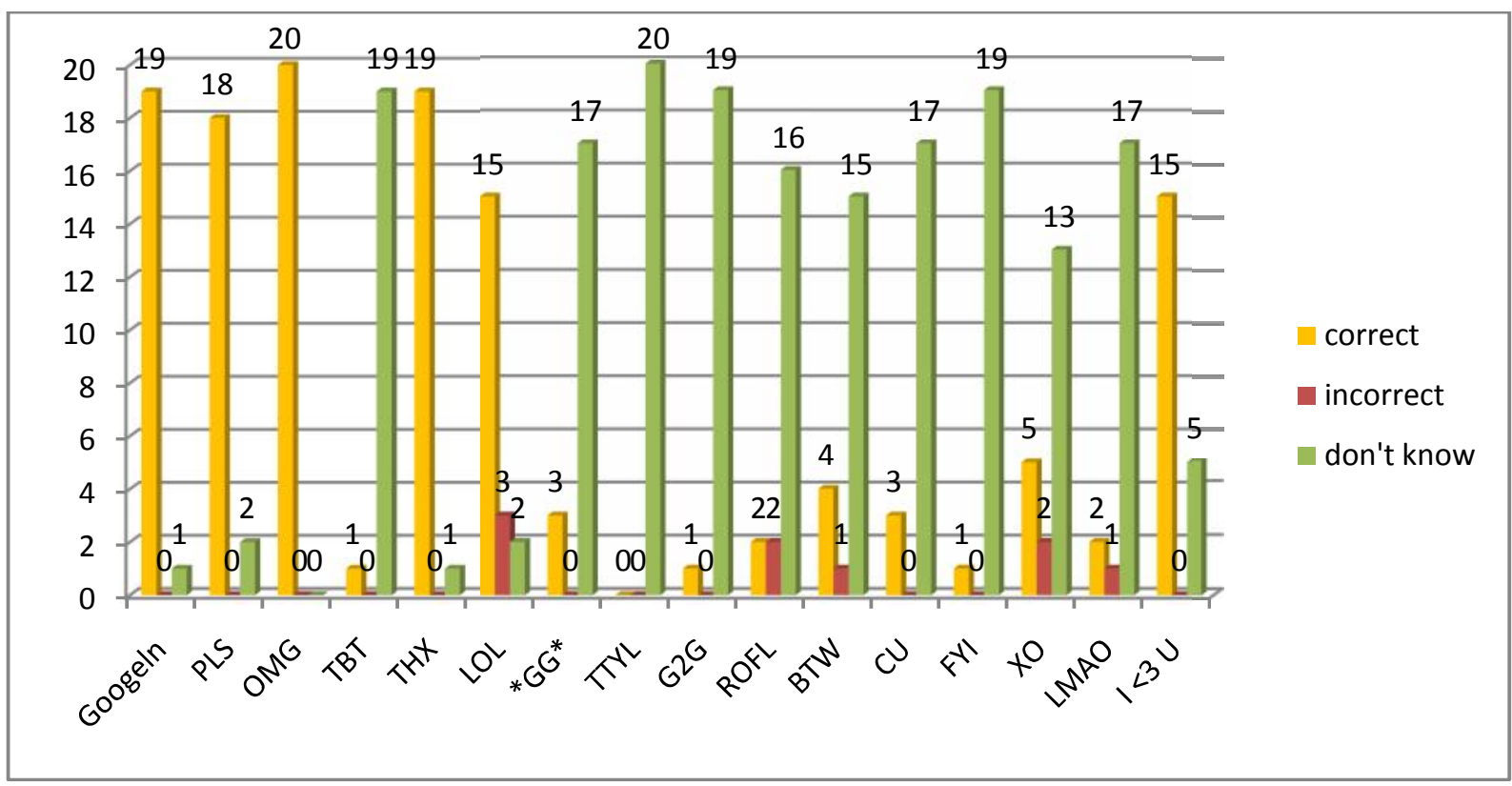

Table 9. Third Grade: Students know what the given netspeak items stand for in English

The results of the section where pupils had to actually write down what these netspeak items stand for are more or less in accord with their claims about knowing how to use them correctly. Almost all students, in fact, know that googeln, OMG and THX stand for looking something up on the internet, oh my god and thanks (table 6). In particular, 19 pupils knew the correct word behind the item THX and the correct meaning of googeln, and even 20, i.e. all, participants knew what $O M G$ stands for. Mirroring the results of the previous table, the majority of the subjects were able to give correct words for $P L S, L O L$ and $I<3 U$. Concerning $L O L$, however, three wrong answers were given, which consisted of wrong spellings or wrong word use. As was to be expected, most students did not know the answers to the same netspeak items of which they were not sure of how to use them correctly in German context. 


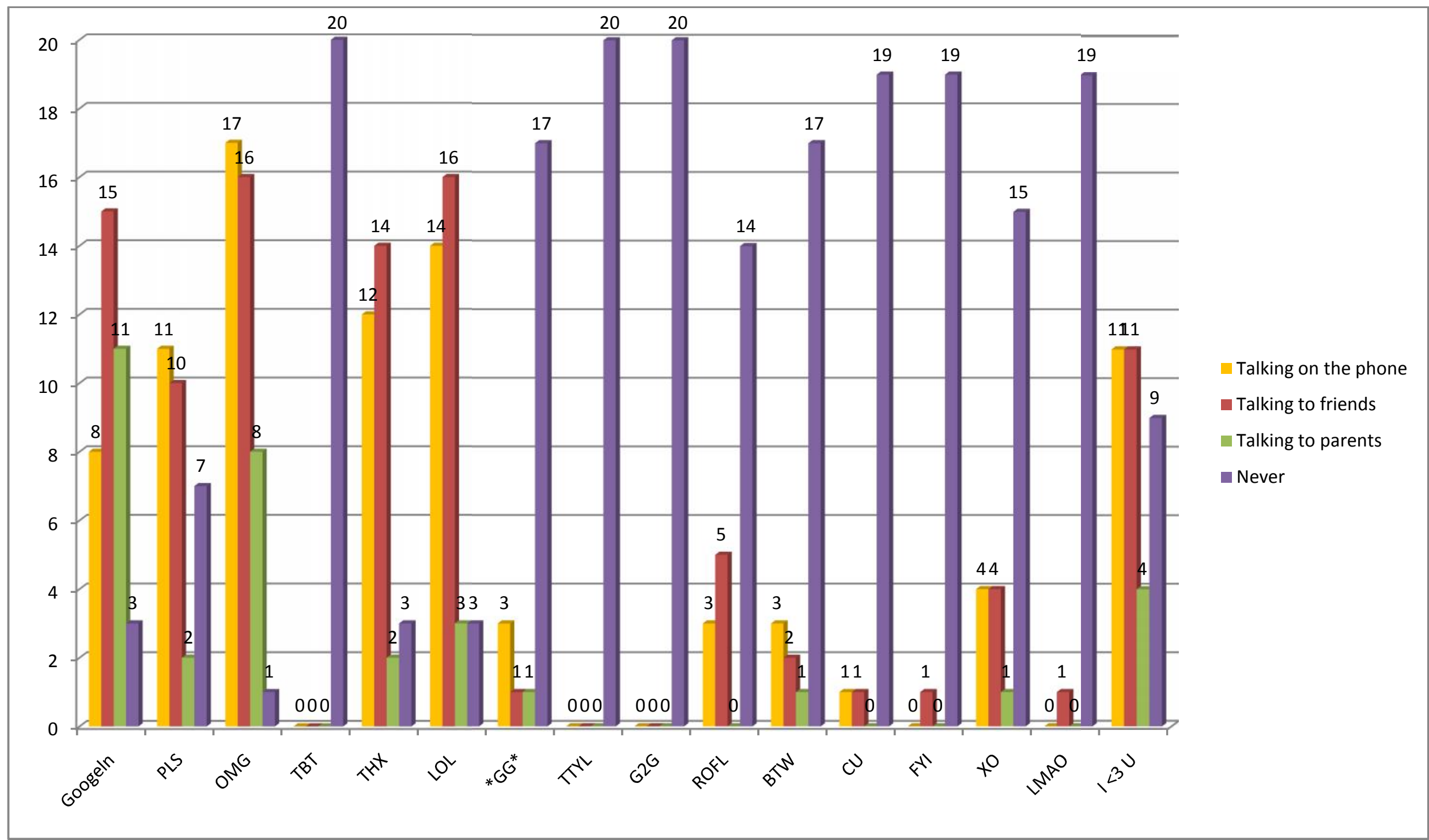

Table 10. Third Grade: When students use the given netspeak elements in spoken German 


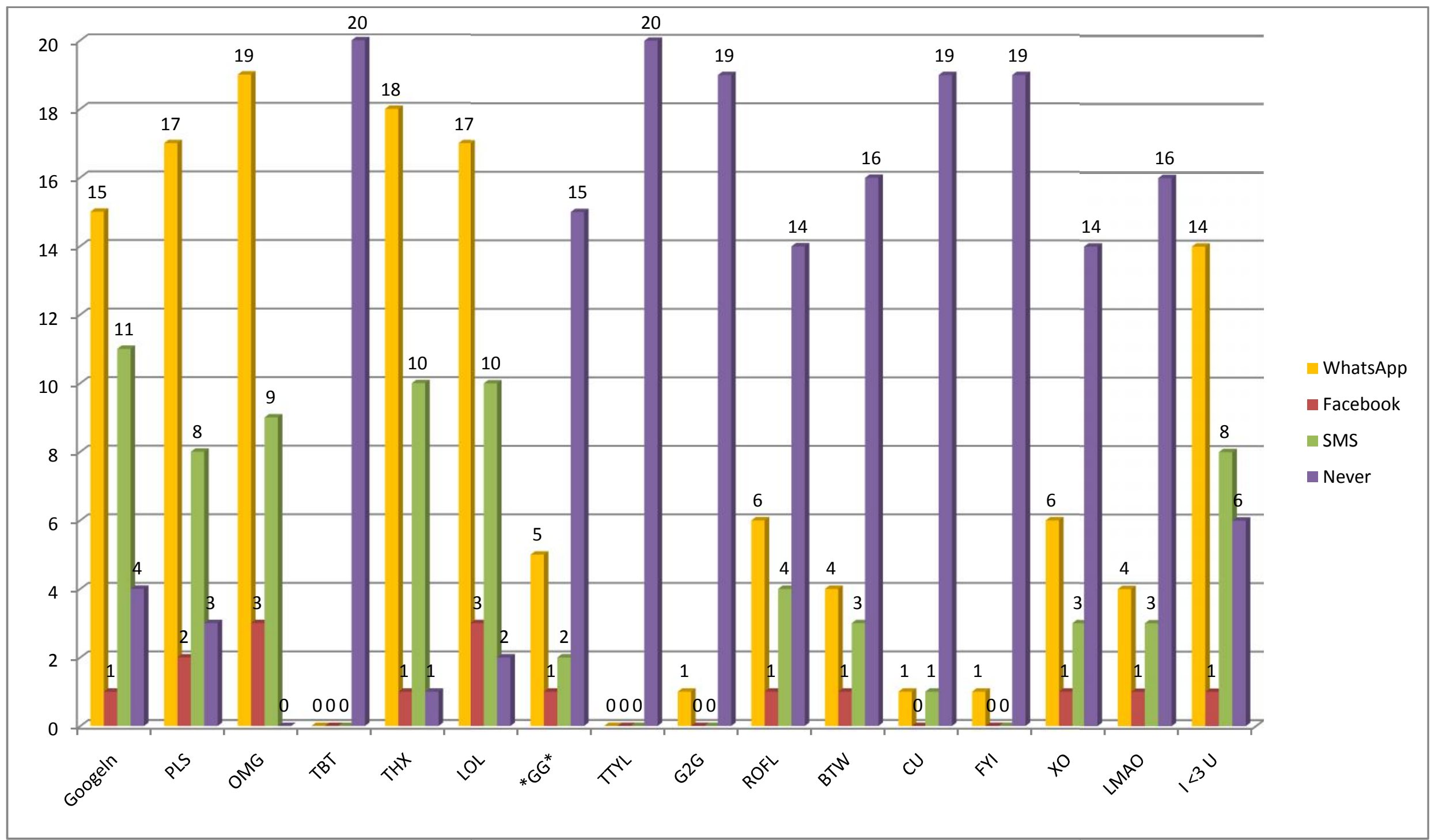

Table 11. Third Grade: Where students use the given netspeak elements in German writing 
Table 7 shows that those netspeak items that are used by the participants are commonly rather used on the phone and more frequently in conversations with friends than with parents. Googeln, OMG, THX and $L O L$ were the ones most selected by participants and are, as already implied, mostly used when talking to friends. The most infrequent items seem to be $T B T$, TTYL and $G 2 G$, which were not chosen once. However, this question could have been misinterpreted by participants, which would make the findings of table 6 questionable. The original goal of this particular question was to find out if students use internet language orally too, not only in written language, which was identified by the - possible not significant enough - title 5.1. Speaking.

In table 8 , it can be seen that WhatsApp messages have overtaken the outdated SMS, as those netspeak items that are commonly used in German writing are more frequently sent via WhatsApp than via SMS. Additionally, Facebook does not seem to play a big role amongst the subjects aged 12 to 14 . Furthermore, 85 percent of the students state that they use $O M G, T H X, L O L$ and $P L S$ and they use them rather in WhatsApp messages (66,6 percent) than in traditional SMS $(33,3)$. 


\subsubsection{Results of the Seventh Grade}

The results of the seventh grade are also organised in tables, like those of the third grade. There was a total number of 23 pupils in this class, eleven boys and twelve girls aged between 16 and 17.

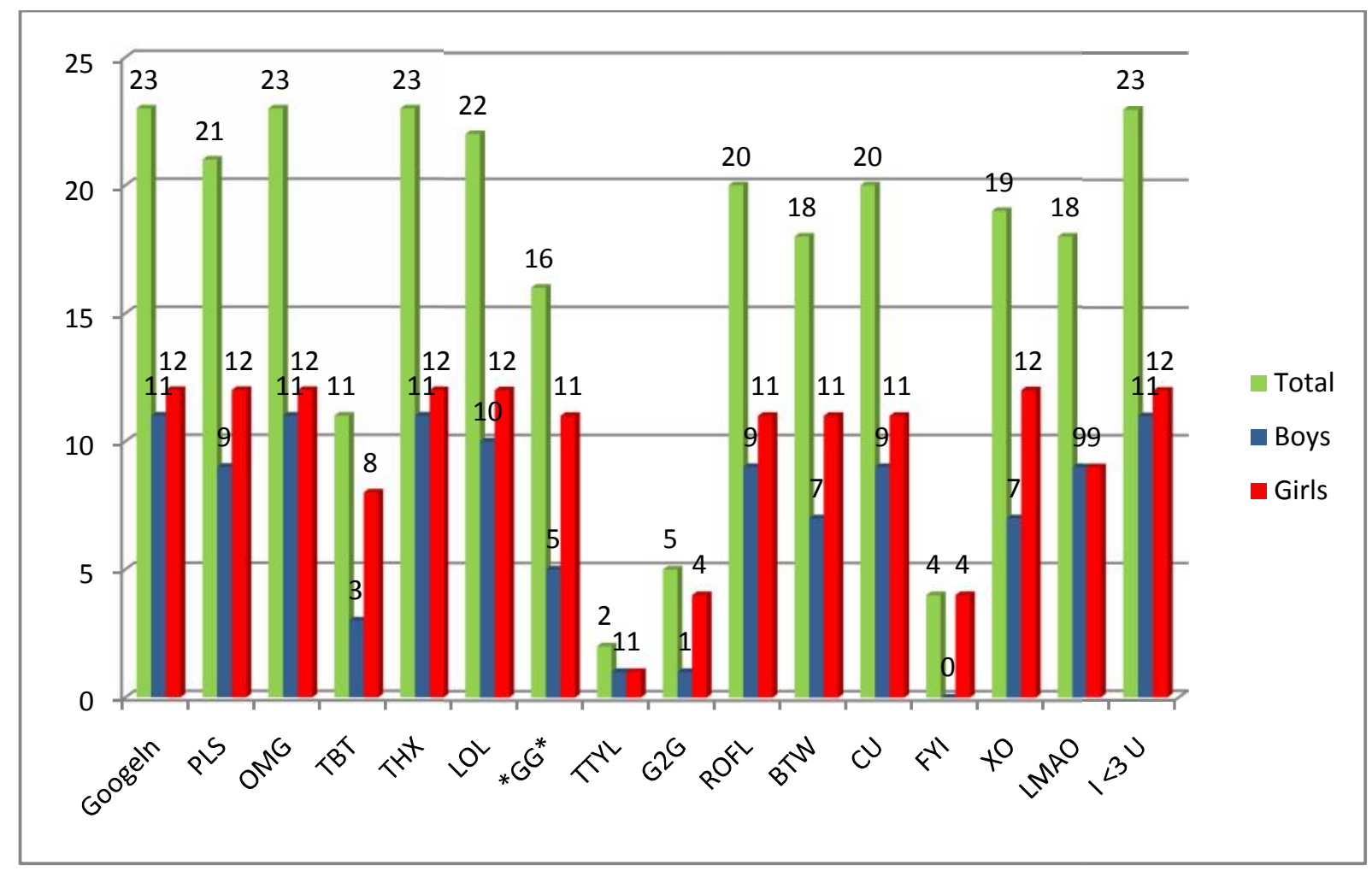

Table 12. Seventh Grade: Netspeak items students have heard of

Table 9 shows that most of the seventh graders have heard of the majority of the internet language items given. Nearly all of the students knew the items googeln, OMG, THX, LOL, $P L S$ and $I<3 U$, which is very similar to the third grade's answers. However, $P L S$ and $I<3 U$ were not quite as popular amongst the 12 to 14 year olds as amongst the 16 to 17 year olds. Especially the popularity of $I<3 U$ differs between younger students and older ones: In the third grade almost only girls knew the item, whereas in the seventh grade all of the subjects, i.e. eleven boys and twelve girls, have heard of $I<3 U$. These differing outcomes could be explained by the different interests of younger children and teenagers. Students have not or only rarely heard of the items TTYL, G2G and FYI. 


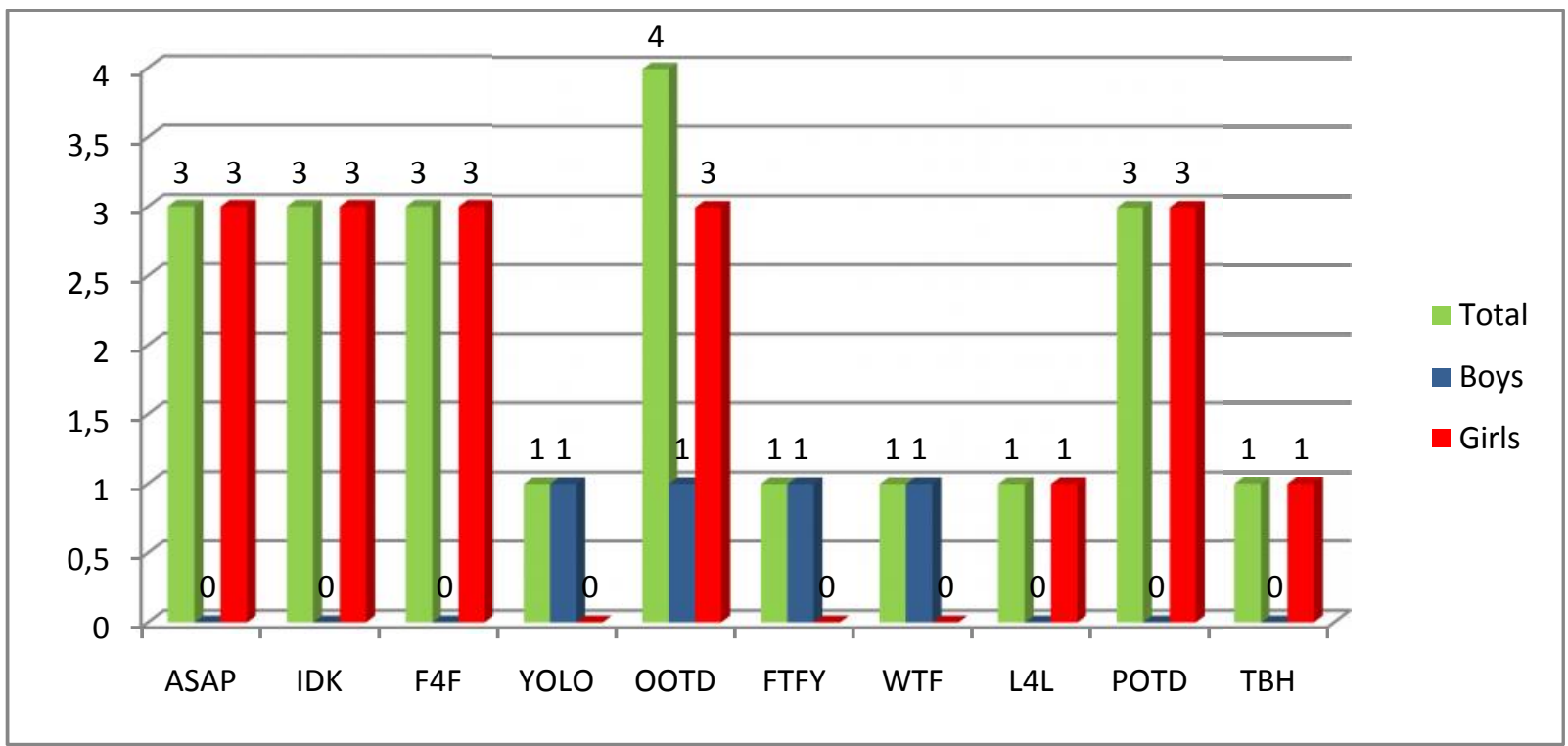

Table 13. Seventh Grade: Other netspeak items students have heard of

Table 10 gives additional netspeak items mentioned by the subjects, of which a few are swear words, just like in the third grade. The acronyms that were added are ASAP (as soon as possible), IDK (I don't know), F4F (follow for follow), YOLO (you only live once), FTFY (fixed that for you), WTF (what the fuck), L4L (like for like), POTD (picture of the day), TBH (to be honest) and OOTD (outfit of the day). OOTD was not surprisingly listed only by girls, since it has to do with fashion and clothes. 


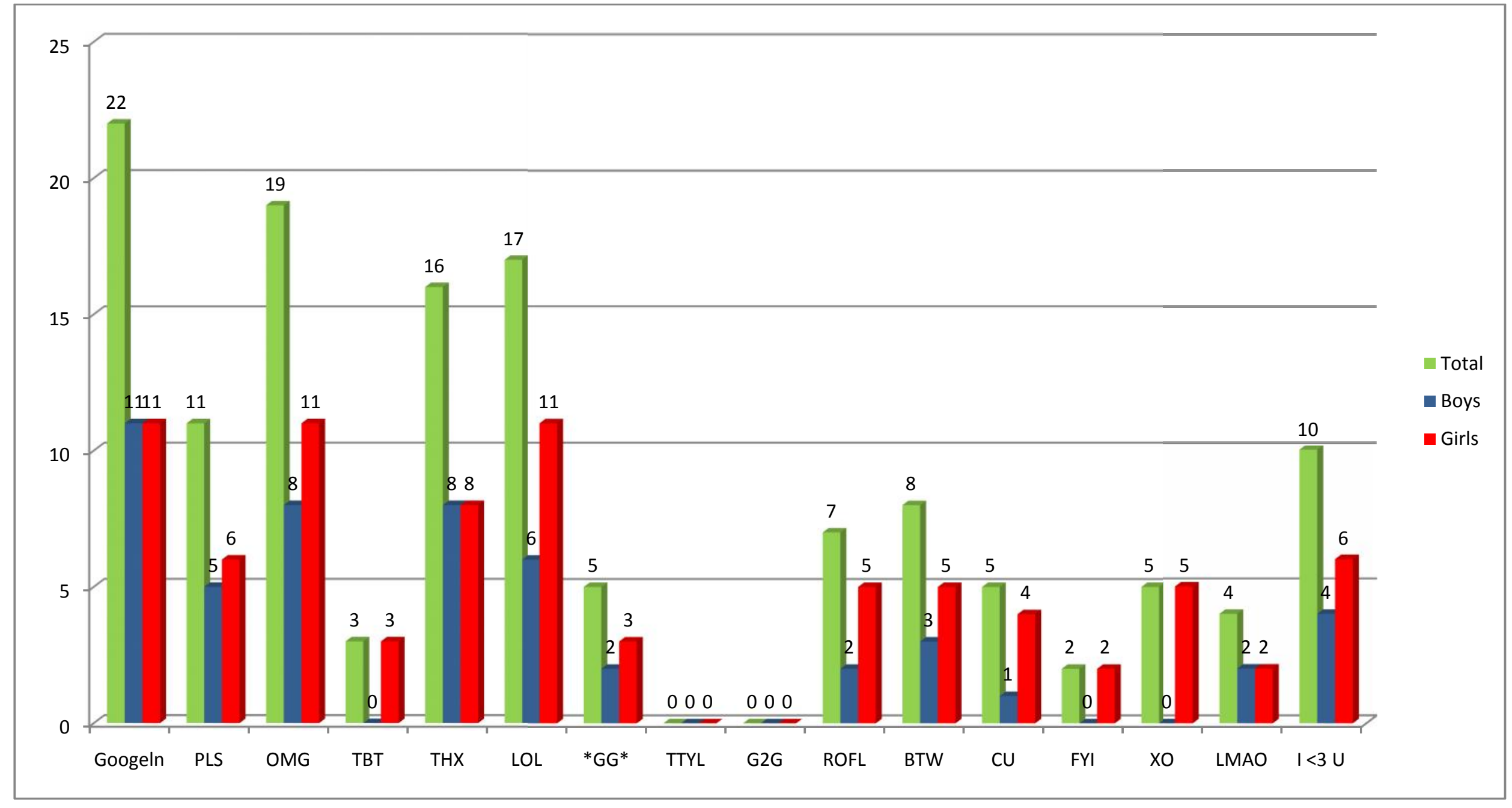

Table 14. Seventh Grade: Netspeak items students use in German writing or speaking 
In table 11, it becomes obvious that there is not a great difference in the use of netspeak items between the third and the seventh grade. Googeln, OMG, THX and LOL are also the most frequently used items amongst the older students. $L O L$, however, is used a lot more by third graders than by seventh graders. What immediately struck me when I compared these findings to the third grade was that in the seventh grade the netspeak item $I<3 U$ is used by boys almost as frequently as by girls.

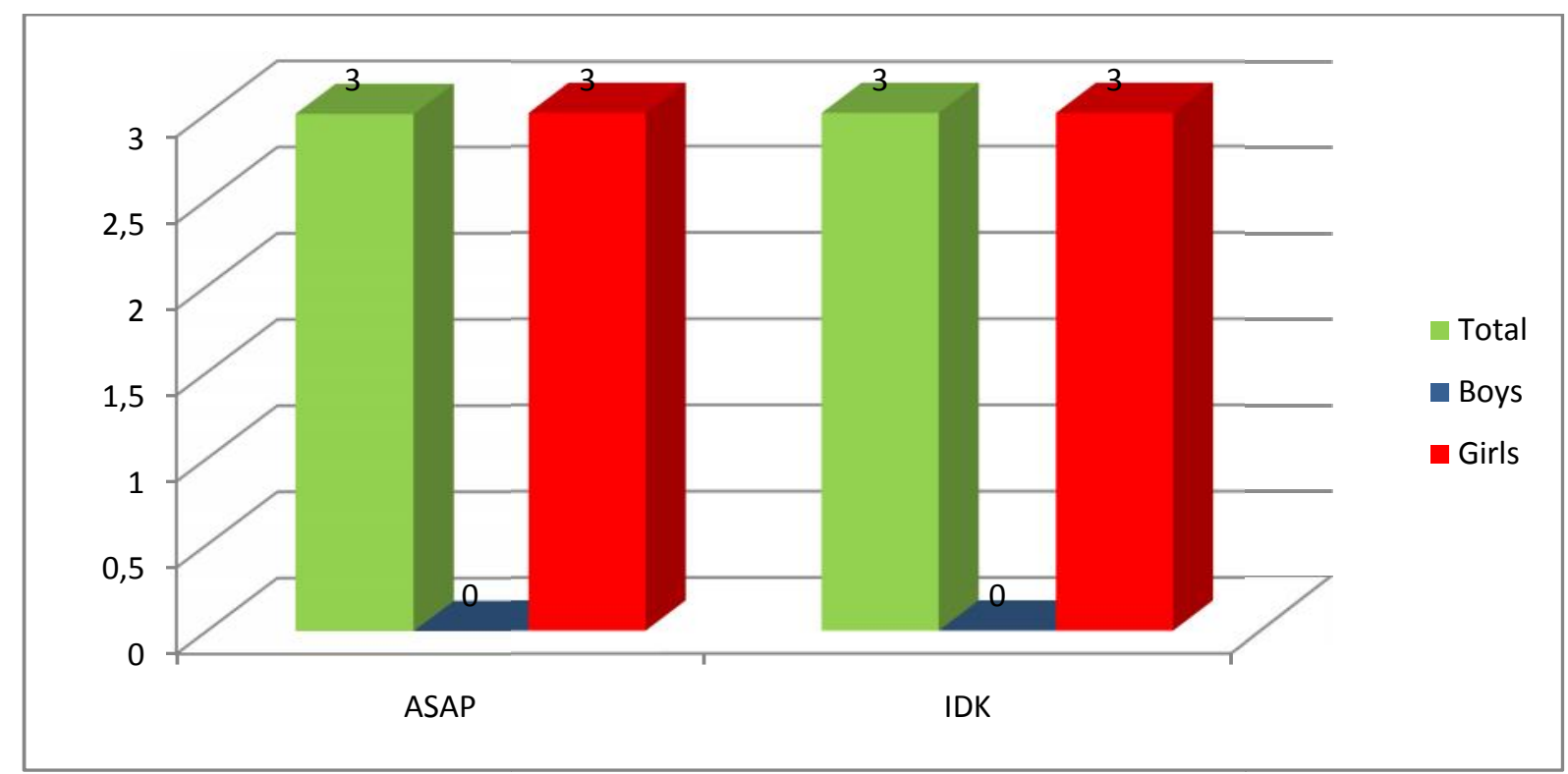

Table 15. Seventh Grade: Other netspeak items students use in German writing or speaking

The subjects gave two more English netspeak elements which they also use in their German writing and speaking, namely ASAP (as soon as possible) and IDK (I don't know). These acronyms were both listed three times, by girls (table 12). 


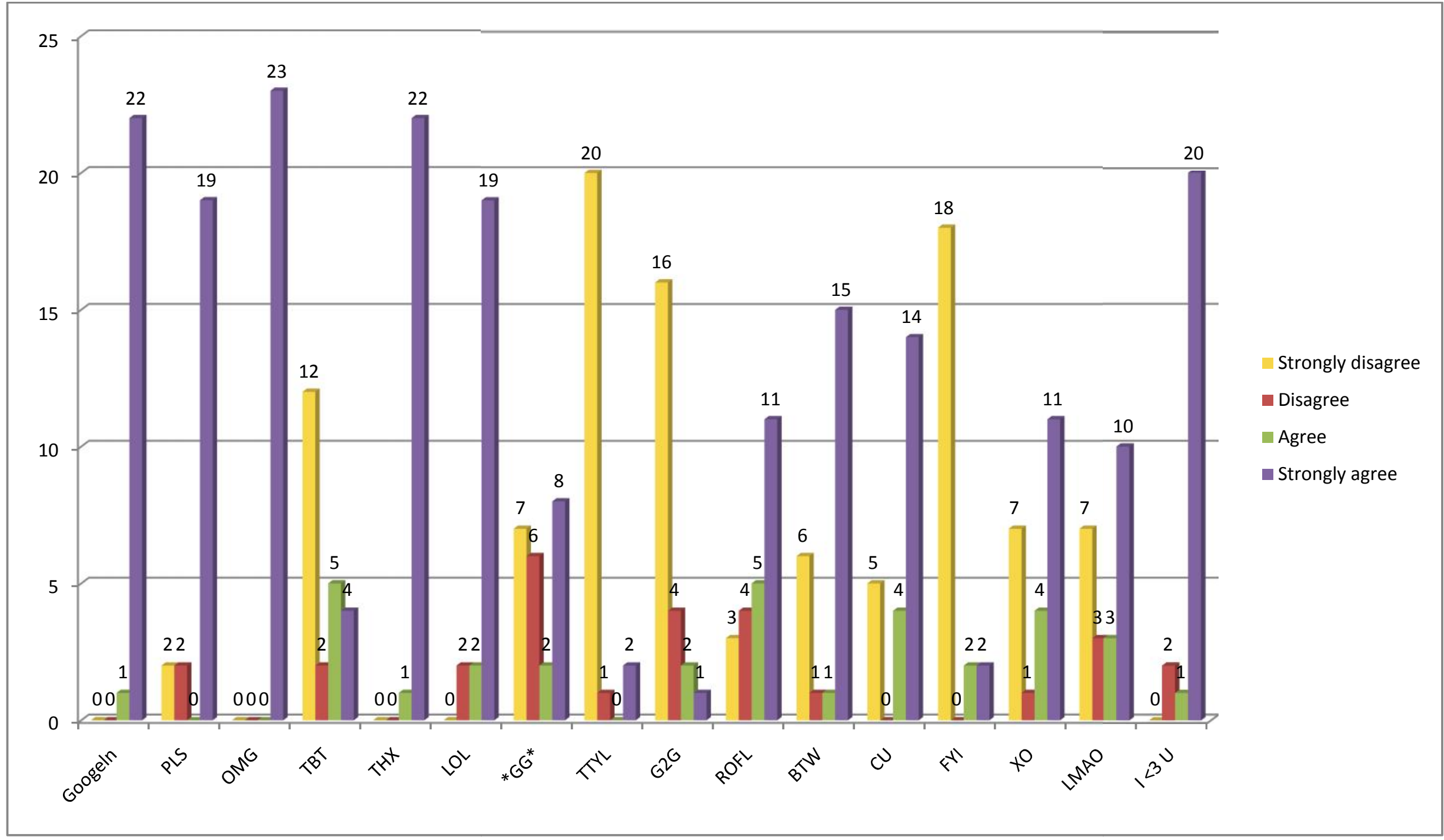

Table 16. Seventh Grade: Students know how to use these netspeak items in German writing or speaking 
In table 13, we can see that only few of the given netspeak elements seem to create serious problems for seventh graders. Almost none of the subjects knew how to use the following three items correctly in German writing or speaking: TTYL, G2G and FYI. Those seem to be the only ones in the list that still present difficulties in the seventh grade. Nearly all of the pupils were sure that they knew how to use googeln, OMG,LOL, PLS and THX. In comparison to the third grade, many more seventh graders stated that they knew how to use $P L S$ and $T H X$ than did third graders.

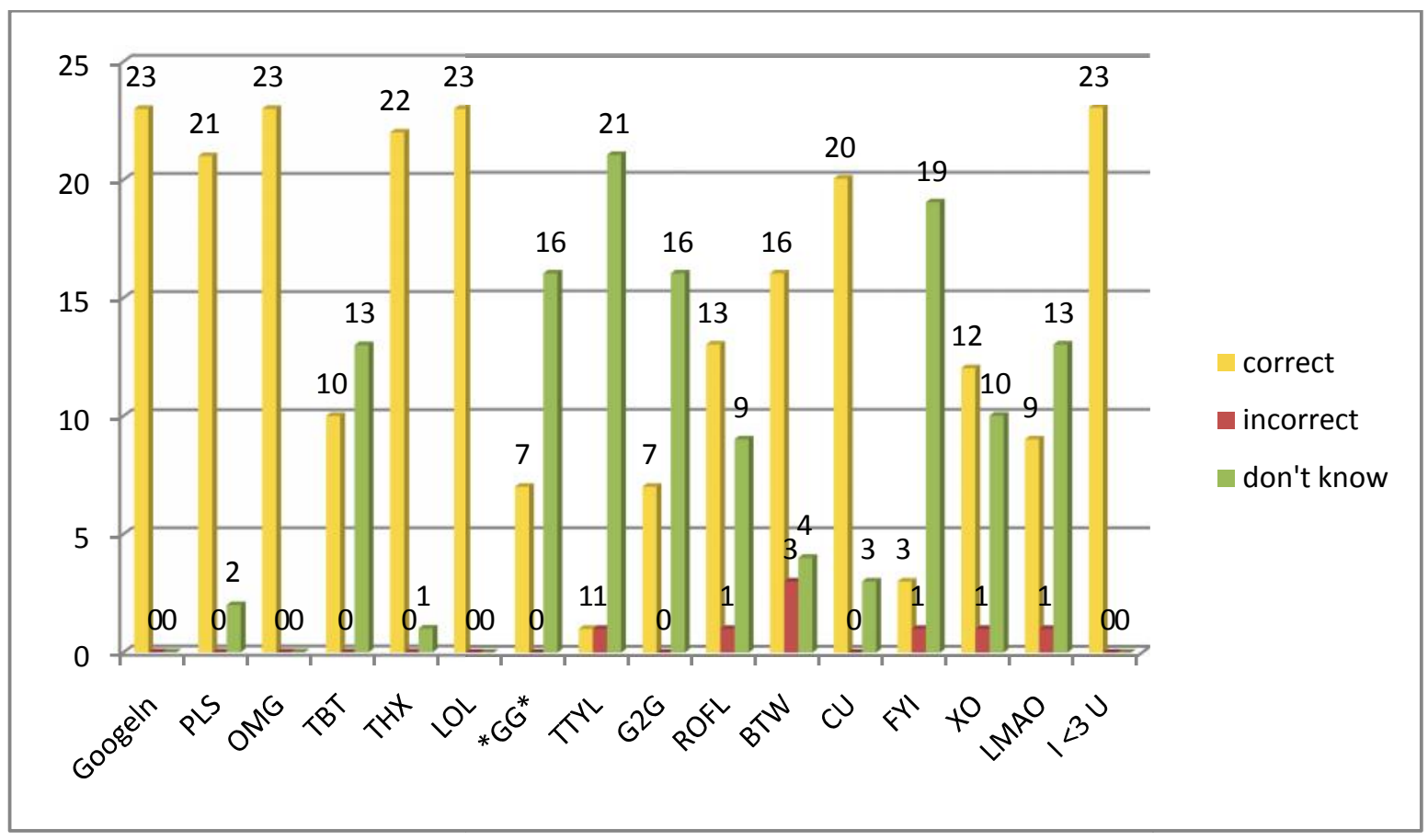

Table 17. Seventh Grade: Students know what the given netspeak items stand for in English

Table 14 shows that nearly all of the elder students knew the meaning and words of seven of the listed items, namely googeln, OMG, THX, PLS, LOL, I <3 U,CU. There was only significant lack of knowledge when it came to the two items TTYL and FYI, only one subject knew what TTYL stands for and three which words are hidden in FYI. This could have been guessed by looking at the answers of the previous table, as students admitted to not knowing how to use these two items correctly. 


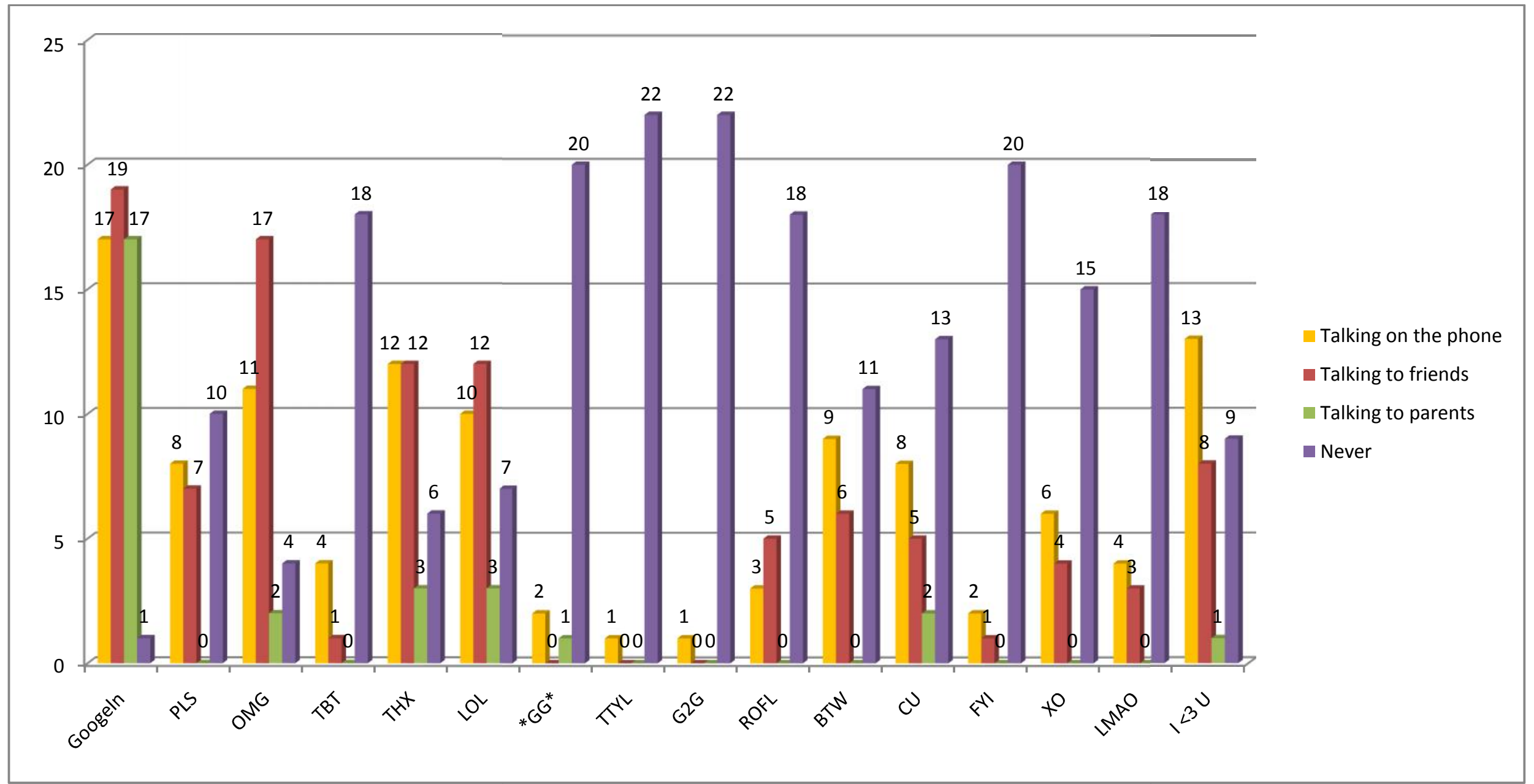

Table 18. Seventh Grade: When students use the given netspeak elements in spoken German 


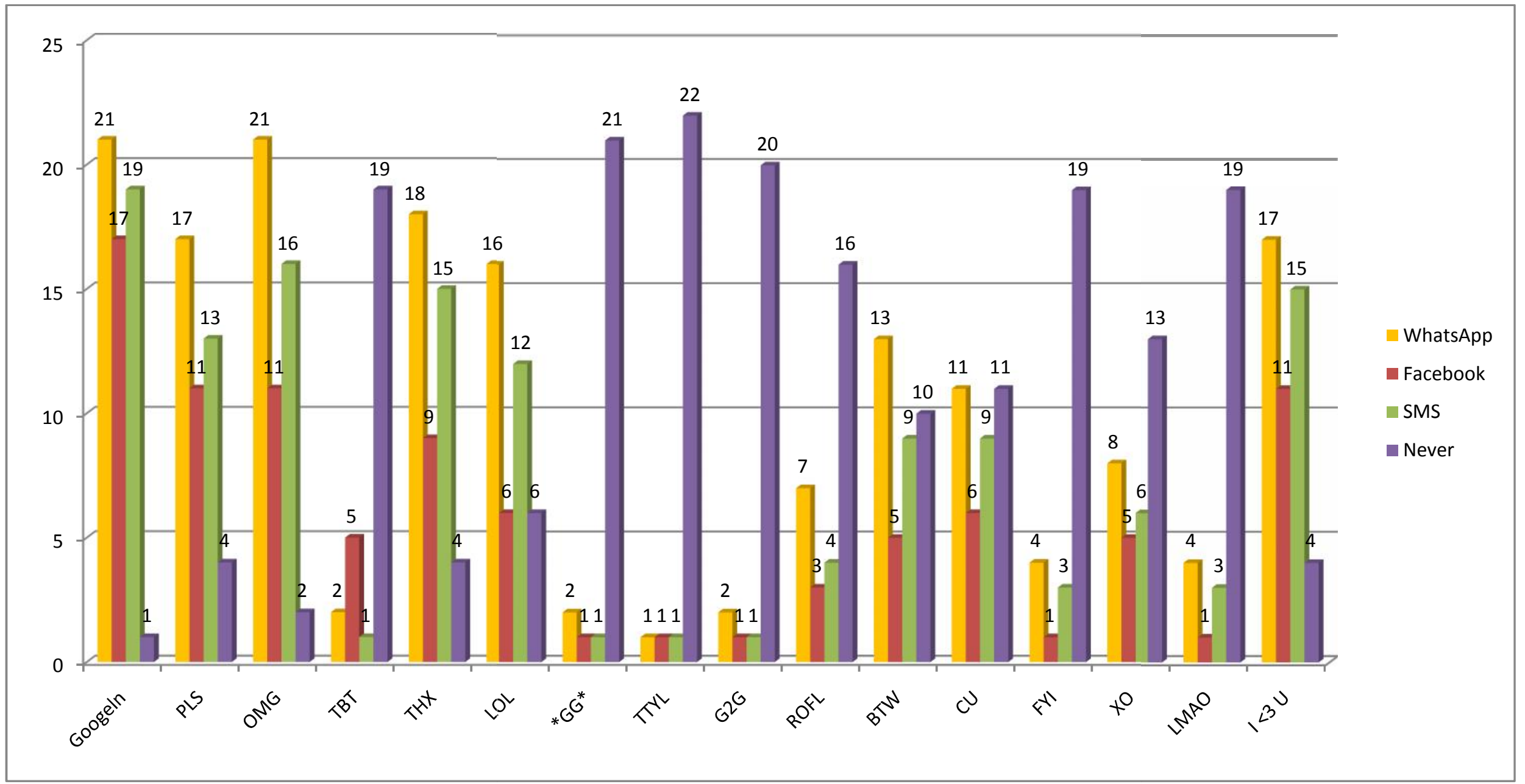

Table 19. Seventh Grade: Where students use the given netspeak elements in German writing 
In table 15, it can be seen that internet language items are, in general, more common amongst friends than in conversations with parents. Googeln and $O M G$ seem to be the only elements actually said aloud by students of the seventh grade, of which googeln is almost used as much in conversations with friends as with parents. However, ${ }^{*} G G^{*}, T T Y L, G 2 G, R O F L, F Y I$ and $L M A O$ are never used in spoken language by most participants. This question could have been misinterpreted by participants, which would make the findings of table 14 questionable. The original goal of this particular question was to find out if students use internet language orally too, not only in written language, which was identified by the - possibly not significant enough - title 5.1. Speaking.

For written language, table 16 reveals quite a different outcome compared to the third grade's results. In general, WhatsApp and SMS seem to be equally important for this age group, which means that internet language items are not used significantly more on WhatsApp than in SMS. Secondly, Facebook seems to play a much bigger role for older students than for younger ones. Netspeak items are, however, not used as frequently on Facebook as they are used on WhatsApp and in SMS. The most commonly used elements are googeln, OMG, THX, PLS and $I<3 \mathrm{U}$, whereof googeln is used nearly to the same extent on WhatsApp, Facebook and SMS. OMG is, by far, mostly used on WhatsApp; and PLS, THX and $I<3 U$ are commonly used on both WhatsApp and SMS, and only half of the subjects using these items also type them into Facebook. 


\subsubsection{Significant Differences Between Third and Seventh Grade}

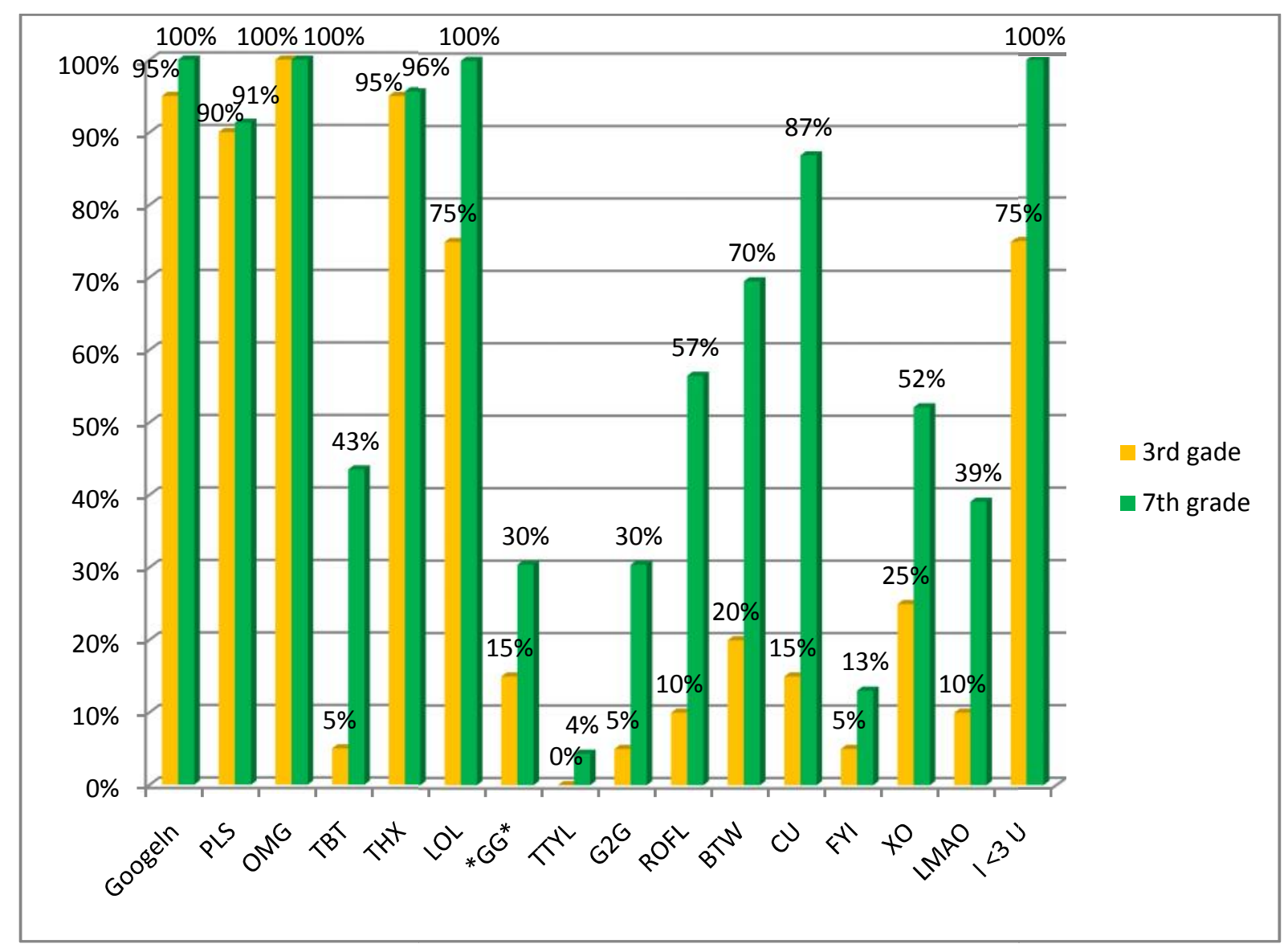

Table 20. Comparing third and seventh grade: Students know what the given netspeak items stand for in English

It seemed highly interesting to investigate if the level of the second language English is important or even decisive when it comes to knowledge about the netspeak items. For this reason, the knowledge on internet language of the third was compared to that of the seventh grade. Differences could indeed be detected in the answers of seventh graders (table 17): While the percentage of subjects who knew what googeln, PLS, OMG and THX (the most frequent items) stand for was the same in the third and seventh grade, the meaning of other internet language elements such as $R O F L, B T W, C U$ and $L O L$ were known to significantly more seventh graders than third graders. The meaning of $L O L$, in particular, seem to create trouble for younger students; some of them did not know the exact words even though they had apparently heard them before and gave answers such as laughing out laugh and laugh without laugh, of which the second one does not make any sense whatsoever. This suggests that the level of English does play a role in the knowledge of internet language items. 


\section{Conclusion}

The two teacher interviews proved to be very informative as both teachers have already been teaching children and teenagers for a long period of time. They were, therefore, able to sum up all their experience about cross-linguistic influence in second language acquisition in these interviews. From their answers, it can be concluded that the language learners' mother-tongue German definitely has a great influence on the learners' phonological and lexical achievements in the second language.

In terms of phonology and phonetics, it seems that there are two types of sounds that are often transferred from the L1 German to the L2 English: those sounds that do not exist in German at all, such as th (they) and $\alpha$ (apple); and those sounds that do exist in the German language but are pronounced differently in English, such as $v$ like in the German word Vase and the English word very [verI], or the German $w$ like in the word Welt and the English version of $w$ like in the word world [ $\left[\begin{array}{ll}\mathrm{w} & \mathrm{ld}\end{array}\right]$.

When it comes to lexical transfer, the English word order appears to be the main problem. Students tend to transfer the German word order to the English language and produce samples like then went $I$ in the early stages of learning English. In addition, pupils obviously have difficulties choosing the right prepositions in word phrases such as an example of where they often use for instead of of, which could derive from German as the phrase is used with the preposition für (for) in German.

It is not entirely clear if beginners or advanced students commit more lexical transfer. On the one hand, students with a higher level of English have a more extensive vocabulary, which, in turn, could mean that they are confused more easily and thus cannot tell if a word derives from English or from German. Beginners, on the other hand, could transfer more lexical items from German to English as they might help themselves by referring back to their first language due to the lack of knowledge of English lexis. This would have to be investigated in more detail and by means of more teacher interviews.

Generally, it can be stated that there is more lexical transfer in written work than in speaking. The reason for this seems to be that more complex structures and words are used in (especially formal) texts; structures and words which students sometimes do not know how to use. Therefore, existing linguistic knowledge of the mother-tongue is used to compensate this 
lack. In spoken language, however, pupils can easily describe words they do not know and therefore do not have to use their first language to help them.

Interestingly, both teachers agree that L1 transfer is not a severe problem in school. They, generally, conclude that learning a second language is about understanding each other and thus being able to communicate successfully. This means that language transfer ought to be prevented from the beginning on. Teachers should provide extensive input, rather than pointing out every transfer students make, as long as it does not hinder successful communication.

Concerning the influence of English internet language on German speaking pupils who are learning English as a second language, it can definitely be said that there is an impact of English netspeak on the German language. Even though almost all of both the beginners and the advanced students have heard of the netspeak items googeln, OMG, THX, PLS and $L O L$, (many of them of several other items too), they only use the three items googeln, OMG and $L O L$ in their everyday communication in their native language German. In comparison to the third grade, however, the seventh grade uses these items less frequently, according to their answers in the questionnaire. $T H X$ is not used as often as the other four items mentioned before, however, it is still used much more often than PLS.

The results of the most interesting question to me, namely, if the level of English predetermines different knowledge about specific internet language items, are striking. Most importantly, against expectations, there was no significant difference in the most common items googeln, OMG, PLS and THX between beginners and advanced students. The same amount of pupils of the third grade compared to the seventh grade know what these four elements mean. What was detected, however, is that a considerably higher number of seventh graders knows what less popular netspeak items such as $C U, B T W$ and ROFL stand for. In addition, slightly fewer pupils from the third grade can give the exact words that $L O L$ stands for. This might have to do with the lower level of English and the accompanying fact that the beginners' cannot yet differentiate spoken English as exactly as advanced students (if their knowledge derives from having already heard the words somewhere).

On the whole, it has been proven that the mother-tongue of a second language learner influences his or her performance in the second language in several ways. In addition, a new type of language, namely the English internet language, seems to have a significant impact on 
pupils' everyday German language. This implies that the first and second language are interconnected in the brain to some extent, as otherwise language transfer would not exist. 


\section{Bibliography}

Adjemian, Christian (1983)."The Transferability of Lexical Properties". In: Susan Gass and Larry Selinker, eds. Language Transfer in Language Learning. Rowley, Mass.: Newbury House. 250-268.

Arabski, Janusz (ed.) (2006). Cross-linguistic Influences in the Second Language Lexicon. Clevedon: Multilingual Matters.

Ard, Josh and Taco Homburg (1983). "Verification of Language Transfer". In: Susan Gass and Larry Selinker, eds. Language Transfer in Language Learning. Rowley, Mass.: Newbury House.157-176.

Bauer, Laurie (1983). English Word-formation. Cambridge: University Press.

Beauvillain, C. and J. Grainger (1987). "Accessing Interlexical Homographs: Some limitations of a language-selective access. In: Journal of Memory and Language 26. 658-672.

Beckner Clay et al. (2009). "Language Is a Complex Adaptive System: Position Paper". In: Nick C. Ellis and Diane Larsen-Freeman, eds. Language as a Complex Adaptive System. Michigan: Wiley-Blackwell. 1-26.

Birdsong, David (2014). "Introduction: Whys and Why Nots of the Critical Period Hypothesis for Second Language Acquisition". In: David Birdsong, ed. Second Language Acquisition and the Critical Period Hypothesis.1-22.

Bongaerts, Theo (2014). "Ultimate Attainment in L2 Pronunciation: The Case of Very Advanced Late L2 Learners". In: David Birdsong, ed. Second Language Acquisition and the Critical Period Hypothesis. 133-160.

Bosch, L., A. Costa and N.Sebastián-Gallés (2000). "First and Second Language Vowel Perception in Early Bilinguals". In: European Journal of Cognitive Psychology. 12. 189-221.

Brown, R. and D. MacNeil (1996). "The Tip of the Tongue Phenomenon". In: Journal of Verbal Learning and Behaviour. 5. 325-327. 
Caramazza, A. and I. Brones (1979). "Lexical Access in Bilinguals". In: Bulletin of the Psychonomic Society 13. 212-214.

Cieslicka, Anna (2006). "On Building Castles on the Sand, or Exploring the Issue of Transfer in the Interpretation and Production of L2 Fixed Expressions". In: Janusz Arabski, ed. Cross-linguistic Influences in the Second Language Lexicon. Clevedon: Multilingual Matters.

Collins, A. M. and M. R. Quillan (1969). "Retrieval Time from Semantic Memory". In: Journal of Verbal Learning and Behaviour. 8. 240-247.

Cook, V. (1992). "Evidence for Multicompetence". In: Language Learning 42. 557-591.

Cook, V. (2003). "Introduction: The Changing L1 in the L2 User's Mind". In: V. Cook, ed. Effects of the Second Language on the First. Clevedon: Multilingual Matters.

Corder, S. Pit (1973). Introducing Applied Linguistics. London: Penguin.

Corder, S. (1978). "Language-learner Language". In: J. Richards, ed. Understanding Second and Foreign Language Learning. Rowley: Newbury House. 71-93.

Cristoffanini, P. et al. (1986). "Bilingual Lexical Representation: The Status of SpanishEnglish Cognates". In: Quarterly Journal of Experimental Psychology. 39A. 367-393.

Crystal, David (2011). Internet Linguistic: A Student Guide. Oxon: Routledge.

De Angelis, Gessica (2007). Third or Additional Language Acquisition. Clevedon: Multilingual Matters.

De Angelis, Gessica and Jean-Marc Dewaele (eds.) (2011). New Trends in Crosslinguistic Influence and Multilingualism Research. Bristol: Multilingual Matters.

De Bot, Kees et al. (2011). "Introduction". In: Marjolijn H. Verspoor et al., eds. A Dynamic Approach to Second Language Development. Amsterdam: John Benjamins B.V. 1-4.

De Bot, Kees and Diane Larsen-Freeman (2011). "Researching Second Language Development from a Dynamic System Theory Perspective". In: Verspoor et al., eds. A dynamic Approach to Second Language Development. Amsterdam: John Benjamins. $5-24$. 
Ellis, Rod (2007). Second Language Acquisition. [1997]. Oxford: Oxford University Press.

Fantini, Alvino (1985). Language Acquisition of a Bilingual Child. Clevedon: Multilingual Matters.

Flege, J. E. and R. D. Davidian (1984). "Transfer and Developmental Processes in Adult Foreign Language Speech Production". In: Applied Psycholinguistics. 5. 323-347.

Flege, James E. (2014). "Age of Learning and Second Language Speech". In: David Birdsong, ed. Second Language Acquisition and the Critical Period Hypothesis. 101132.

Gabrys-Barker, Danuta (2006). "The Interaction of Languages in the Lexical Search of Multilingual Language Users". In: Janusz Arabski, ed. Cross-linguistic Influences in the Second Language Lexicon. Clevedon: Multilingual Matters. 144-166.

Gass, Susan M. and Larry Selinker (eds.) (1992). Language Transfer in Language Learning. Amsterdam/Philadelphia: John Benjamin Publishing.

Grodd, Wolfgang, Dirk Wildgruber and Vinod Kumar (2009). "Functional Imaging of Language Competent Brain Areas". In: Grzegorz Dogil and Susanne Maria Reiterer, eds. Language Talent and Brain Activity. Berlin: Mouton de Gruyter. 131-154.

Hansen, Jette G. (2006). "Investigating L2 Phonology". In: Acquiring a Non-Native Phonology. London: Continuum. 7-39.

Hodne, B. (1985). "Yet Another Look at Interlanguage Phonology: The Modification of English Syllable Structure by Native Speakers of Polish". In: Language Learning. 35 (3). 405-417.

Hurford, J. (1994). Grammar: A Student's Guide. Cambridge: Cambridge University Press.

James, Allan R. (1988). The Acquisition of a Second Language Phonology: A Linguistic Theory of Developing Sound Structures. Tübingen: Gunter Narr Verlag.

Johnson, J.S. and Newport E.L. (1989). "Critical Period Effects in Second Language Learning: The Influence of Maturational State on the Acquisition of English as a Second Language". In: Cognitive Psychology. 21. 60-99. 
Kellerman, Eric (1987). Aspects of Transferability in Second Language Acquisition. Nijmegen: University of Nijmegan.

Klein, W. (1995). Language Acquisition at Different Ages. In: D. Magnusson, ed. The Lifespan Development of Individuals: Behavioral, Neurobiological, and Psychosocial Perspectives. A Synthesis. Cambridge: Cambridge University Press. 244-264

Kleinmann, Howard (1977). "Avoidance Behaviour in Adult Second Language Acquisition". In: Language Learning. 27. 93-107.

Krashen, Stephen (1983). "Newmark's Ignorance Hypothesis' and current second language acquisition theory". In: Susan Gass and Larry Selinker, eds. Language Transfer in Language Learning. Rowley, Mass.: Newbury House.

Lado, Robert (1957). Linguistics Across Cultures. Ann Arbor: University of Michigan Press.

Lehr, F., Osborn, O.J. and Hiebert E.H. (2004). A Focus on Vocabulary. Honolulu: Pacific Resources for Education and Learning.

Lenneberg, E.H. (1967). Biological Foundations of Language. New York: Wiley.

Long, M (1990). Maturational Constraints on Language Development. In: Studies in Second Language Acquisition. 12. 251-285.

Major, R. C. (1987). "A Model for Interlanguage Phonology". In: G. Ioup and S. H. Weinberger, eds. Interlanguage Phonology: The Acquisition of a Second Language Sound System. Cambridge: Newbury House Publishers. 101-124.

McClelland, J. L. and D.E., Rumelhart (1981). "An Interactive Activation Model of Conetxt Effects in Letter Perception Part 1: An Account of the Basic Findings". In: Psychological Review. 88. 375-407.

Mehler, J., E. Dupoux, C. Pallier \& G. Dehaene-Lambertz (1994). "Cross-linguistic Approaches to Speech Processing". In: Current Opinion in Neurobiology. 4. 171-176.

Müller, Sarah (2007). The Mental Lexicon. München: GRIN Publishing GmbH.

Neufeld, Gerald (1978). "On the Acquisition of Prosodic and Ariculatory Features in Adult Language Learning". In: Canadian Modern Language Review. 34. 163-174. 
Odlin, Ternece (1989). Language Transfer: Cross-linguistic Influence in Language Learning. Cambridge: Cambridge University Press.

Oyama, Susan (1976). A Sensitive Period for the Acquisition of a Nonnative Phonological System. In: Journal of Psycholinguistic Research. 5. 261-285.

Patowski, M. (1990). "Age and Accent in a Second Language: A reply to James Emil Flege". In: Applied Linguistics. 11. 73-89.

Perfetti, C. A., Y., Liu, J., Fiez, J. Nelson, D. J. Bolger \& L.-H. Tan (2007). "Reading in Two Writing Systems: Accommodation and Assimilation of the Brain's Reading Network". In: Bilingualism: Language and Cognition. 10 (2).131-146.

Piske, T., Flege, J.E., MacKay, I.R.A. and Meador, D. (2002)."The Production of English Vowels by Fluent Early and Late Italian-English Bilinguals". In: Phonetica. 59 (1).4971.

Purcell, Edward and Richard, Suter (1980). "Predictors of Pronunciation Accuracy: A Reexamination". In: Language Learning. 30. 271-287.

Randall, Mick (2007). Memory, Psychology and Second Language Learning. Amsterdam: John Benjamin Publishing.

Ringbom, Hakan (1986). "Crosslinguistic Influence and the Foreign Language Learning Process". In: Eric Kellerman and Michael Sharwood Smith, eds. Influence in Second Language Acquisition. Press Crosslinguistic New York: Pergamon.

Ringbom, Hakan (1987). The Role of the First Language in Foreign Language Learning. Clevedon: Multilingual Matters.

Ringbom, Hakan (2006). "The Importance of Different Types of Similarity in Transfer Studies". In: Janusz Arabski, ed. Cross-linguistic Influences in the Second Language Lexicon. Clevedon: Multilingual Matters. 36-45.

Rubin, G. S., C. A. Becker and R. H. Freeman (1979). "Morphological Structure and its Effects on Visual Word Recognition". In: Journal of Verbal Learning and Behaviour. 18. 757-767. 
Sato, C. J. (1984). "Phonological Processes in Second Language Acquisition: Another Look at Interlanguage Syllable Structure". In: Language Learning. 34 (4).43-57.

Schachter, Jacquelyn (1974). "An Error in Error Analysis". In: Language Learning 24. 205214.

Scovel, T. (1969). "Foreign Accents, Language Acquisition, and Cerebral Dominance". In: Language Learning. 19. 245-253.

Scovel, T. (1988). A Time to Speak: A Psycholinguistic Inquiry into the Critical Period for Human Speech. Rowley, MA: Newbury House.

Scovel, T. (2000). "The Younger, the Better: Myth and Bilingual Education". In: R. D. González and I. Melis, eds. Language Ideologies: Critical Perspectives on the Official English Movement. Mahwah, NJ: Lawrence Erlbaum Associate.114-136.

Seliger, H., Kraschen, S. and Ladefoged P. (1975). "Maturational Constraints in the Acquisition of Second Language Accent". In: Language Sciences. 36. 20-22.

Selinker, L. (1972). "Interlanguage". In: IRAL. 10/3. 31-54.

Siegler, Robert, Judy DeLoache and Nancy Eisenberg (2011). Entwicklungspsychologie im Kindes- und Jugendalter. German translation by Sabine Pauen. Spektrum Akademischer Verlag: Heidelberg.

Singleton David (2007). "How Integrated is the Integrated Mental Lexicon?". In: Zsolt Lengyel and Judit Navracsics, eds. Second Language Lexical Processes: Applied Linguistic and Psycholinguistic Perspectives. Clevedon: Multilingual Matter Ltd. 316.

Singleton, David (2014). "Is there a Best Age for Learning a Second Language?". In: Vivian Cook and David Singleton, eds. Key Topics in Second Language Acquisition. Bristol: Multilingual Matters. 17-36.

Singleton, David (2014). "How Do People Acquire the Words of a Second Language?". In: Vivian Cook and David Singleton, eds. Key Topics in Second Language Acquisition. Bristol: Multilingual Matters. 37-54. 
Sjöholm, Kaj (1976). "A Comparison of the Test Results in Grammar and Vocabulary Between Finnish- and Swedish-speaking Applicants for English". In: Hakan Ringbom and Rolf Palmberg, eds. Errors Made by Finns and Swedish-Speaking Finns in the Learning of English. Abo, Finland: Department of English, Abo Akademi. ERIC Report ED 122628.

Sweet, Henry (1988/1972). The Practical Study of Languages. London: Oxford University Press.

Tarone, E.(1980). "Some Influences on the Syllable Structure of Interlanguage Phonology". In: IRAL. XVIII (2). 138-52.

VanPatten, Bill and Alessandro G. Benati (2010). Key Terms in Second Language Acquisition. London: Continuum.

Wunder, Eva-Maria (2011). "Crosslinguistic Influence in Multilingual Language Acquisition: Phonology in Third or Additional Language Acquisition". In: Gessica De Angelis and Jean-Marc Dewaele, eds. New Trends in Crosslinguistic Influence and Multilingualism Research.Bristol: Multilingual Matters. 105-127.

Zhang, Y. and Y. Wang (2007). "Neural Plasticity in Speech Acquisition and Learning". In: Bilingualism: Language and Cognition. 10 (2).147-160.

\section{Electronic Sources}

Abello-Contesse, Christian (2008). "Age and the Critical Period Hypothesis". In: ELT Journal. [online]. http://eltj.oxfordjournals.org/content/63/2/170.full. [2015, March 10]

Davies, Mark. (2008-). The Corpus of Contemporary American English: 450 million words, 1990-present. [online]. http://corpus.byu.edu/coca/. [2015, March 13].

Farah, Villie and Amy Carson (2011). "The History of Blogging". In: Bright Hub. http://www.brighthub.com/internet/web-development/articles/109149.aspx. [2015, March 12)]. 
"Mother

$$
\text { Tongue" }
$$

(n.d.).

Oxford

Dictionaries

[Online].

http://www.oxforddictionaries.com/de/definition/englisch/mother-tongue [2014, Dec. 3]

"Mother Tongue" (n.d.). Cambridge Dictionaries Online.[Online] http://dictionary.cambridge.org/dictionary/british/mother-tongue [2014, Dec. 3]

"Taxonomy of Learning Theories" [online] https://ryan2point0.wordpress.com/2010/01/12/taxonomy-of-learning-theories/ [2015, March 9]

Wesson, Kenneth (2010). "Neuroplasticity". In: Brain World. [online]. http://brainworldmagazine.com/neuroplasticity/. [2015, March 10] 